\title{
WEDGES, LABOR MARKET BEHAVIOR, AND HEALTH INSURANCE COVERAGE UNDER THE AFFORDABLE CARE ACT
}

\author{
Trevor S. Gallen \\ Casey B. Mulligan \\ Working Paper 19770 \\ http://www.nber.org/papers/w19770
NATIONAL BUREAU OF ECONOMIC RESEARCH
1050 Massachusetts Avenue
Cambridge, MA 02138 \\ December 2013
}

We appreciate comments from workshop participants at the University of Chicago, the Atlanta Fed, and the financial support of the George J. Stigler Center for the Study of the Economy and the State. The views expressed herein are those of the authors and do not necessarily reflect the views of the National Bureau of Economic Research.

NBER working papers are circulated for discussion and comment purposes. They have not been peerreviewed or been subject to the review by the NBER Board of Directors that accompanies official NBER publications.

(C) 2013 by Trevor S. Gallen and Casey B. Mulligan. All rights reserved. Short sections of text, not to exceed two paragraphs, may be quoted without explicit permission provided that full credit, including (C) notice, is given to the source. 
Wedges, Labor Market Behavior, and Health Insurance Coverage under the Affordable Care Act

Trevor S. Gallen and Casey B. Mulligan

NBER Working Paper No. 19770

December 2013

JEL No. H3,I13,I18

\begin{abstract}
The Affordable Care Act's taxes, subsidies, and regulations significantly alter terms of trade in both goods and factor markets. We use a multi-sector (intra-national) trade model to predict and quantify consequences of the Affordable Care Act for the incidence of health insurance coverage and patterns of labor usage. If and when the new exchange plans are competitive with employer-sponsored insurance (ESI), our model suggests that more than 20 million people will leave ESI as a consequence of the law. Behavioral changes that are captured in the model could add about 3 million participants to the new exchange plans: beyond those that would participate solely as the result of employer decisions to stop offering coverage and beyond those who would have been uninsured. Industries and regions will grow, decline, and change coverage on the basis of their relative demand for skilled labor.
\end{abstract}

Trevor S. Gallen

University of Chicago

Department of Economics

1126 E. 59th St.

Chicago, IL 60637

tgallen@uchicago.edu

Casey B. Mulligan

University of Chicago

Department of Economics

1126 East 59th Street

Chicago, IL 60637

and NBER

c-mulligan@uchicago.edu

An online appendix is available at:

http://www.nber.org/data-appendix/w19770 
Making healthcare affordable should profoundly affect the labor market, because the poor and unemployed can least afford health expenses and because employers have traditionally financed much of the economy's health spending. A fully implemented Affordable Care Act (hereafter, ACA) has the potential of altering the composition of employers, the demographic composition of the workforce, the size of the workforce, the number unemployed, and the structure of wages.

Presumably the ACA was intended to reshape the market for healthcare, but not the market for labor. Perhaps those intentions explain why, so far, forecasts of various effects of the ACA hold constant most, if not all, labor market outcomes. ${ }^{1}$ The purpose of our paper is to fill this gap by quantifying new incentives created by the ACA and modeling labor market behavioral responses to them.

The ACA is a large and complex piece of legislation. This paper emphasizes four types of provisions in the law: the means-tested subsidies for health insurance premiums and out-ofpocket expenses for persons who are not offered affordable health insurance by an employer (hereafter, "exchange subsidies," which go into effect January 1, 2014), the monetary penalties on employers who do not offer health insurance to their full-time employees (going into effect January 1, 2015), the monetary penalties on uninsured persons, and the major medical reinsurance assessment. ${ }^{2}$ We also consider the interactions of these provisions with pre-existing payroll, personal income, and business income tax rules, and the so-called "family glitch" with

\footnotetext{
${ }^{1}$ For example, the Congressional Budget Office's Health Insurance Simulation Model (Congressional Budget Office 2007) and RAND's Comprehensive Assessment of Reform Efforts (Eibner and Price 2012) forecast effects on the composition of employee compensation and the overall cost of health insurance, but not the level of employee compensation, the size of the workforce, etc. See also the studies surveyed by Buchmueller, Carey and Levy (2013). ${ }^{2}$ The ACA creates health insurance "marketplaces" or "exchanges" where individuals can purchase health insurance. The insurance premium subsidies created by the law are administered so that they reduce what participants pay for insurance plans obtained on the exchanges.
} 
the exchange subsidies. ${ }^{3}$ We model the possibility that various ACA provisions may not be fully implemented, enforced, or fully considered by households.

Our model features a health insurance decision that depends on taxes, subsidies, and administrative costs, broadly interpreted. Aside from possible tax benefits, a producer may offer health insurance to her employees because employees demand a cash wage premium to work for an employer that does not offer insurance. In our model, producers are heterogeneous in terms of the skill-intensity of their production technology and their costs of administering health insurance. Because administrative costs are passed on to consumers through output prices, market forces induce the producers with low administrative costs to hire more employees, especially those with more skill.

Household labor supply and factor prices are also endogenous in our model. Altogether, tax and subsidy rules affect factor prices and the number of people covered by employersponsored insurance (hereafter, ESI) through four types of behavioral responses: the ESI-offer decision, factor market comparative advantage, consumer substitution, and labor supply.

Our model also features non-group health insurance in the sense that employers can choose to forgo the subsidy implicit in the exclusion of ESI costs from the personal income and payroll tax bases, and let their employees obtain health insurance in a non-group market in which the real administrative costs are related to what they would be if they had obtained insurance through their employer. Absent the ACA, our model offers little reason for workers to obtain non-group health insurance because of the implicit tax subsidy for ESI. In contrast, the ACA offers subsidies that vary by worker skill and thereby attract a specific part of the population into the non-group market. Under both regimes, a segment of the population prefers to be uninsured because they face administrative costs and insurance loadings that are too large to justify the purchase of either ESI or non-group coverage. Our model therefore has quantitative predictions as to the number of people covered by health insurance and the composition of that coverage.

Our model features heterogeneous sectors, some of which can be interpreted as “entrepreneurial" or intensive in small establishments. However, we do not model the ACA's

\footnotetext{
${ }^{3}$ See also Mulligan (2013) on interactions between ACA provisions, unemployment insurance, and uncompensated health care.
} 
significant employer-size provisions in any detail. ${ }^{4}$ Our paper does not specifically model health outcomes. We look at the entire labor market, but doing so prevents us from explicitly modeling any one industry's organization and performance. These simplifications allow us to tractably derive quantitative results for various important labor market behaviors that previous authors have held constant, and to help the reader readily understand the origins of our results.

Section I of the paper sets up the model with an algebraic representation of tastes, technologies, public policies, and market equilibrium. Section II characterizes an equilibrium's qualitative properties. Section III calibrates the model, with special emphasis on measuring the startling size of the new tax wedges between sectors and skill groups. Section IV presents quantitative predictions for the impact of the ACA on the amount and incidence of insurance coverage. A companion paper (Mulligan and Gallen 2013) presents our model's quantitative predictions for the impact of the ACA on wages and aggregate output. Section V concludes.

\section{Model Setup}

\section{Tastes and Technologies}

Producers differ according to their costs of administering health insurance. Broadly interpreted, this administrative cost can reflect employee turnover, economies of scale, abilities to self-insure, abilities to minimize adverse selection, insurance loadings, etc. For each unit of insured labor rented by a firm in sector $i, 1-e^{-\delta(i)}<<1$ units must be devoted to health insurance administration, and the remaining $e^{-\delta(i)}<1$ devoted to producing for the firm's customers.

We assume that uncompensated care and Medicaid have some undesirable characteristics and that, if health insurance administrative costs were zero, workers would prefer private insurance to both of these options. We let $\chi>0$ quantify the undesirable characteristics, such as the amounts that uninsured individuals are required to pay for their health care, the (imperfect) quality and accessibility of uncompensated care and Medicaid, and the extra financial risks associated with being uninsured. In reality, some of these costs of being uninsured are monetary

\footnotetext{
${ }^{4}$ See Gallen (2013), who also models the distinction between part-time and full-time work.
} 
costs, and others utility costs, but for simplicity we model $\chi$ as foregone output. For each unit of uninsured labor rented by a firm, $e^{-\chi}<1$ units are devoted to producing for the firm's customers, with the remaining $1-e^{-\chi}<<1$ units representing foregone employee healthcare product attributes. If firms and employees were not taxed on the basis of health insurance offerings, a firm $i$ with employees whose only reasonable source of insurance is through the employer would maximize their joint interests by offering ESI if and only if $\chi>\delta(i)$.

The differences among producers in the costs of administering health insurance appear to be large, because significant increases in the implicit subsidy (associated with exclusion from income and payroll tax bases) failed to make ESI universal among employers - especially small employers, and significant subsidy cuts fail to eliminate ESI - especially among large employers (Congressional Budget Office 2007). All else the same, employers suffering from ESI administration disadvantages would essentially disappear from the marketplace, but of course all else is not the same. Firms may produce distinct products, and consumers may be willing to purchase the goods and services produced by firms that cannot efficiently administer ESI. Small firms may enjoy other advantages that help offset advantages of administration enjoyed by their larger competitors. We capture both of these effects by having (a) multiple sectors in our model whose outputs are imperfect substitutes in utility and (b) allowing consumer preferences to vary across sectors.

Sectors also differ according to the skill-intensity of their technologies. Sector $i$ 's technology is:

$$
y(i)=z(i) e^{-\delta(i) I N S(i)-[1-I N S(i)] \chi}\left[(1-\alpha(i)) K(i)^{(\sigma-1) / \sigma}+\alpha(i) A(i) L(i)^{(\sigma-1) / \sigma}\right]^{\sigma /(\sigma-1)}
$$

where $K(i)$ is the amount of high-skill labor employed in sector $i, L(i)$ is the amount of low-skill labor employed in sector $i, y(i)$ is sectoral output, the constants $z(i)$ are sector $i$ 's overall productivity, $\sigma$ is the elasticity of substitution in production, $A(i)$ is a sector $i$ low-skill labor biased technology term, and the $\alpha_{i}$ 's are share parameters. ${ }^{5} \operatorname{INS}(i)$ is an indicator variable for

\footnotetext{
${ }^{5}$ As shown in equation (1), our model has constant returns to the two types of labor, and no explicit reference to physical capital inputs. We interpret equation (1) as a long run value function or reduced form that implicitly accounts for physical capital accumulation in proportion to the amount of labor. Equation (1) is not well suited for analysis of public policies, such as capital income taxes, that would change the long run capital-labor ratio. As noted below, our interpretation is related to interpretations of some of the sectoral substitution elasticities.
} 
whether firms in sector $i$ offer ESI or, under the ACA, have employees who obtain affordable non-group coverage through the "exchanges."

Let $i \in[0,1]$ denote quantiles of the administrative cost distribution. Given that we observe firms that do not offer health insurance have relatively low-skill employees, we suspect that $\alpha$ and $\delta$ are positively correlated. For simplicity, we assume a one-to-one monotonic relationship between $\alpha$ and $\delta$, so that $i$ also denotes quantiles of the $\alpha$ distribution.

\section{Public Policy Parameters}

$w$ and $r$ denote the factor rental rates (inclusive of the costs of employee fringe benefits, if any) of low- and high-skill labor, respectively. Inclusive of taxes and subsidies, firms in sector $i$ pay factor rental rates for low-skill labor and high-skill labor that are, respectively:

$$
\left(1+\tau_{i L}\right) w, \quad\left(1+\tau_{i K}\right) r
$$

where $\left\{\tau_{i L}, \tau_{i K}\right\}$ are sector-specific factor tax rates (subsidy rates, if negative). We assume that $\tau_{i L}$ and $\tau_{i K}$ are common to all producers making the same INS decision (more below on the INS decision). The four primary examples of these tax rates are employer payroll taxes, the peremployee penalties for failing to offer affordable health insurance, subsidies for purchasing nongroup insurance, the individual penalties for failing to purchase insurance, and the subsidy implicit in the exclusion of ESI costs from the personal income and payroll tax bases.

The ultimate incidence of the taxes and subsidies does not depend on whether employers or employees pay them, so we assume that $\tau_{i L}$ and $\tau_{i K}$ are paid by employers and adjust empirical estimates of factor prices appropriately to conform to our normalization. We assume that the taxes and subsidies are close enough to zero that each sector's equilibrium marginal product of high-skill labor exceeds its marginal product of low-skill labor (equilibrium is formally defined below).

\footnotetext{
${ }^{6}$ Medicaid and uncompensated care are included in the INS $=0$ category. Thus, INS $=1$ might be described as having private health insurance.
} 
$\tau_{i L}$ and $\tau_{i K}$ do not include taxes or subsidies related to the labor supply decision, like unemployment insurance, the taxes paid on personal income not spent on health insurance, and employee payroll taxes. ${ }^{7} s_{L}$ and $s_{K}$ denote the combined marginal tax rates from the taxes related to the labor supply decision. The marginal rewards to working are therefore $\left(1-s_{L}\right) w$ and $\left(1-s_{K}\right) r$ for low- and high-skill persons, respectively.

Table 1 displays empirical concepts of employee compensation and employer costs, and relates them to our model's notation. Only low-skill notation is shown; high-skill notation would merely replace " $L$ " with " $K$." The top row is total employer cost, inclusive of penalties and fringes, with the notation indicated in equation (2). Employee compensation is many times defined to exclude employer penalties and employer payroll taxes, and our notation for that compensation concept is shown in Table 1's second row.

The employee compensation shown in the second row still differs across sectors because employees may receive a personal income and payroll tax advantage by receiving some of their compensation as ESI or receive tax credits for buying health insurance on the exchanges, depending on the sector in which they are employed. The third row subtracts these items, measured relative to the tax credits received by NGI employees, from the second row. The fourth row shows employee compensation net of all payroll and personal income taxes. Our Harberger (1962) equilibrium assumption that, in the presence of sector-specific taxes, employees are indifferent between sectors is visible in the third and fourth rows because the employee amounts are the same in each column.

\section{Household Preferences}

Given an allocation of labor and production across sectors, the representative household's utility would be:

$$
\ln \left[\int_{0}^{1} e^{\rho(i)} y(i)^{(\lambda-1) / \lambda} d i\right]^{\lambda /(\lambda-1)}-\gamma_{L} \frac{\eta}{\eta+1}\left[\int_{0}^{1} L(i) d i\right]^{(\eta+1) / \eta}-\gamma_{K} \frac{\eta}{\eta+1}\left[\int_{0}^{1} K(i) d i\right]^{(\eta+1) / \eta}
$$

\footnotetext{
${ }^{7}$ For ease of measurement, we do include employer payroll taxes in the employer tax rates $\tau_{i L}$ and $\tau_{i K}$.
} 
The $\rho(i)$ 's, $\eta, \lambda, \gamma_{L}$, and $\gamma_{K}$ are preference parameters. The $\rho(i)$ 's reflect consumer preferences for the various sectors. $\lambda$ is the elasticity of sectoral-output substitution in utility. $\eta$ is the Frisch wage elasticity of labor supply. $\gamma_{L}$ and $\gamma_{K}$ parameterize the disutility of work, holding constant the prevalence of insurance among workers and non-workers.

An efficient allocation of labor and INS would maximize (3) subject to the production functions (1), and taking the taste and technology parameters as given. The efficient allocation of INS would be to the sectors $i \leq i^{*}$, with $\delta\left(i^{*}\right) \equiv \chi .^{8}$ However, the purpose of this paper is to consider equilibrium allocations in the presence of taxes and subsidies, which generally are not efficient.

The representative household uses its factor income and a lump sum transfer $b$ to purchase the output of each industry according to the budget constraint:

$$
\int_{0}^{1} p(i) y(i) d i=\left(1-s_{L}\right) w \int_{0}^{1} L(i) d i+\left(1-s_{K}\right) r \int_{0}^{1} K(i) d i+b
$$

where $p(\cdot)$ is the industry pattern of output prices, taken as given by the household. $\left(1-s_{L}\right) w$ and $\left(1-s_{K}\right) r$ are the household's rewards to working its two types of labor net of payroll taxes, personal income taxes, and means-tested subsidies.

\section{Equilibrium Defined}

The insurance choice is one of three options: ESI, non-group insurance (hereafter, NGI) and uninsured. Associated with these three options are three statutory employer tax rates for each skill level: $\tau_{c L}, \tau_{c K}, \tau_{n L}, \tau_{n K}, \tau_{u L}$, and $\tau_{u K}$, respectively. In this way, insurance choice affects production costs.

Given tax rates $\left\{\tau_{c L}, \tau_{c K}, \tau_{n L}, \tau_{n K}, \tau_{u L}, \tau_{u K}, s_{L}, s_{K}\right\}$, taste parameters $\left\{\eta, \lambda, \gamma_{L}, \gamma_{H}\right\}$, the parameter $\chi$ indicating the desirability of private insurance, the factor substitution elasticity $\sigma$, and industry patterns for $\alpha(\cdot), \delta(\cdot), \rho(\cdot), A(\cdot)$, and $z(\cdot)$, an equilibrium is a pair of factor rental rates $w$ and $r$ and

\footnotetext{
${ }^{8}$ For simplicity, we assume that $\delta(i)$ is continuous and decreasing in $i$ and crosses $\chi$ on the interval $i \in[0,1]$.
} 
a list of industry patterns of low-skill employment $L(\cdot)$, high-skill employment $K(\cdot)$, output $y(\cdot)$, prices $p(\cdot)$, and employer coverage decisions such that: (a) the industry patterns of employment and consumption maximize household utility (3) subject to the household budget constraint (4) (taking as given coverage conditions as reflected in $I N S(\cdot)$ ), (b) each industry's production equals household demand for their output, (c) the industry patterns of employment, output, and coverage decisions are consistent with the production function (1), (d) each industry's coverage decision and composition of labor achieves the minimum production cost, (e) and each industry has zero profits. The government budget constraint and national income identity are:

$$
\begin{gathered}
b=\int_{0}^{1}\left[\left(\tau_{i L}+s_{L}\right) w L(i)+\left(\tau_{i K}+s_{K}\right) r K(i)\right] d i \\
Y=\int_{0}^{1}\left[\left(1+\tau_{i L}\right) w L(i)+\left(1+\tau_{i K}\right) r K(i)\right] d i
\end{gathered}
$$

For the purpose of calculating equilibria under various policies, we assume that all insurance is purchased through employers or former employers, but in mapping to the data we distinguish exchange purchases from ESI narrowly defined, and recognize that these two have different subsidy rates. In particular, under the ACA, employers have three choices: (a) to offer employees ESI narrowly defined, which qualifies for the tax subsidy but not the ACA subsidy, (b) to "offer" employees exchange subsidies, which creates penalties and makes the exchange subsidies available, or (c) not to offer any insurance, leaving employees to be uninsured or on Medicaid.

At first glance, it might seem unrealistic that employers in our model that do not offer ESI have a "choice" between non-group coverage and no insurance at all for their employees, and have to incur the same administrative costs (broadly construed to include insurance loadings) for the non-group coverage as they do for ESI. The important assumption is not whether employer (rather than employee) pays the various administrative costs associated with non-group insurance, but a "no free lunch" assumption that the non-group insurance offered on the exchanges will not make insurance administration and overhead costs disappear. ${ }^{9}$

\footnotetext{
${ }^{9}$ See also our companion paper (Mulligan and Gallen 2013) for more discussion of the legal and practical incidence of insurance decisions. As shown below, we find potentially large shifts from ESI to NGI under the ACA, despite assuming no free lunch.
} 


\section{Qualitative Equilibrium Characteristics}

\section{Employment and Coverage Patterns by Sector}

Each of the three alternatives presents the employer with its own rental rates of skilled and unskilled labor, inclusive of the administrative costs, tax costs, and worker disutility of uncompensated care. Consequently, firms have marginal and average costs of production idiosyncratic to their sector. The log per-unit-output cost function for an employer facing a production function of the form (1) is the minimum of the three possibilities:

$$
-\ln z+\min \left\{\begin{array}{l}
\chi+\frac{1}{1-\sigma} \ln \left[(\alpha A)^{\sigma}\left[\left(1+\tau_{u L}\right) w\right]^{1-\sigma}+(1-\alpha)^{\sigma}\left[\left(1+\tau_{u K}\right) r\right]^{1-\sigma}\right] \\
\delta+\frac{1}{1-\sigma} \ln \left[(\alpha A)^{\sigma}\left[\left(1+\tau_{n L}\right) w\right]^{1-\sigma}+(1-\alpha)^{\sigma}\left[\left(1+\tau_{n K}\right) r\right]^{1-\sigma}\right] \\
\delta+\frac{1}{1-\sigma} \ln \left[(\alpha A)^{\sigma}\left[\left(1+\tau_{c L}\right) w\right]^{1-\sigma}+(1-\alpha)^{\sigma}\left[\left(1+\tau_{c K}\right) r\right]^{1-\sigma}\right]
\end{array}\right\}
$$

which are no coverage, NGI coverage, and ESI coverage, respectively. Each of the coverage possibility terms in (6) reflects the fact that the tax rates associated with a coverage decision affect the optimal the skill-intensity of the workforce.

For any particular coverage option, the square bracket term varies by sector only because the technology skill intensity parameter $\alpha$ varies. The only other source of cost variation is the administrative cost term $\delta$, which also increases with the industry index $i$. Each of the three cost terms can therefore be graphed versus $i$, and any one of the schedules will cross any one of the others once, if at all. Thus, the equilibrium industry pattern of coverage decisions partitions the sectoral index scale $i \in[0,1]$ into at most three intervals.

Unless $\tau_{u L}$ were sufficiently large, the uninsured, if any, would be employed at the least skilled end of the scale because those industries have the greatest insurance administrative costs. Absent the ACA, non-group insurance receives no subsidy and is therefore (in our model) dominated by ESI. The equilibrium coverage decisions in this case look like the green schedule 
in Figure 1 with ESI offered by the skill-intensive industries and no insurance offered by the remainder. ${ }^{10}$

Under the ACA, coverage is described by up to three intervals with ESI offered by the most skill-intensive industries because the ACA has $\tau_{c L}>\tau_{n L}$ and $\tau_{c K}<\tau_{n K}$. Employees purchasing NGI are employed in the middle interval. This situation is illustrated by the green and orange schedules in Figure 2.

Equilibrium requires that every sector have the same tax-adjusted marginal rate of transformation between low and high-skill labor, which is equal to a common marginal rate of substitution in utility.

$$
\begin{gathered}
\frac{\alpha(i) A(i)}{1-\alpha(i)}\left(\frac{K(i)}{L(i)}\right)^{1 / \sigma}=\frac{1+\tau_{i L}}{1+\tau_{i K}} \frac{1-s_{K}}{1-s_{L}} \frac{\gamma_{L}}{\gamma_{K}}\left(\frac{L}{K}\right)^{1 / \eta}=\frac{1+\tau_{i L}}{1+\tau_{i K}} \frac{w}{r} \\
L \equiv \int_{0}^{1} L(i) d i, \quad K \equiv \int_{0}^{1} K(i) d i
\end{gathered}
$$

where each employer's tax rates depend on his ESI or NGI decision. For an employer $i^{*}$ the margin between insurance choice $j$ and insurance choice $j^{\prime}$ (for example, moving from ESI to no ESI),

$$
\frac{K_{j}\left(i^{*}\right)}{L_{j}\left(i^{*}\right)}=\left(\frac{1+\tau_{j L}}{1+\tau_{j K}} \frac{1+\tau_{j^{\prime} K}}{1+\tau_{j^{\prime} L}}\right)^{\sigma} \frac{K_{j^{\prime}}\left(i^{*}\right)}{L_{j^{\prime}}\left(i^{*}\right)} \equiv q_{j j^{\prime}}^{\sigma} \frac{K_{j^{\prime}}\left(i^{*}\right)}{L_{j^{\prime}}\left(i^{*}\right)}
$$

With or without the ACA, employers on the margin between two insurance choices will face a different tax wedge from moving to a different insurance choice. Consequently, the coverage decision is not taken in isolation, but associated with a jump in the skill intensity. Absent the ACA, the ESI-uninsured tax wedge term in (8) is different from one and the skill intensity jumps up (moving from low $i$ to high $i$ ) at the equilibrium $i^{*}$. Because the cost envelope does not jump at $i^{*}$, output does not jump either, and the ESI-marginal firm reduces its total employment as it

\footnotetext{
${ }^{10}$ Figures 1 and 2 are equilibrium simulation results using our benchmark parameter values and assuming full implementation of taxes and subsidies. For the moment, Figures 1 and 2 serve only to illustrate qualitative features of our model (our quantitative work is introduced below).
} 
drops ESI. ${ }^{11}$ The small employment effect of dropping ESI is illustrated in Figure 1 by the blue schedule's jump at the $59^{\text {th }}$ percentile.

The same logic applies on the ESI-NGI margin under the ACA: output and cost do not jump at the sector $i^{*}$ that is in equilibrium on the margin between ESI and NGI. The ESImarginal firm increases its total employment and reduces skilled employment as it drops ESI, moving along its isoquant. These two effects of dropping ESI for NGI are illustrated in Figure 2 by the jumps of the blue and red schedules, respectively, at the $44^{\text {th }}$ percentile.

As we compare industries with insurance coverage in Figures 1 and 2, prices (black series) rise with the industry index $i$ because the administrative costs are rising. The administrative costs are irrelevant for comparing uninsured industries' prices. Equilibrium prices and costs fall with $i$ because those with less skill-intensive technologies have the greater factor market comparative advantage in trading employees with the rest of the industries.

The allocation of labor across industries with the same insurance coverage depends on the preference function $\rho(\cdot)$, which could be assumed to follow any number of patterns. We limit our attention to preference functions that are a quadratic function of $i$, and explain below how we calibrate that function. Regardless of the shape of the function, the relative prices and revenues of two sectors $i$ and 0 have to be consistent with their relative amounts produced:

$$
\begin{aligned}
\frac{p_{i}}{p_{0}} & =e^{\rho_{i}-\rho_{0}}\left(\frac{y_{0}}{y_{i}}\right)^{1 / \lambda} \\
\frac{p_{i} y_{i}}{p_{0} y_{0}} & =e^{\rho_{i}-\rho_{0}}\left(\frac{y_{i}}{y_{0}}\right)^{1-1 / \lambda}
\end{aligned}
$$

All industries have revenue equal cost, which means their relative revenues equal their relative costs:

\footnotetext{
${ }^{11}$ Note that the ESI tax exclusion is a greater percentage of low-skill compensation and thereby biasing ESI sectors toward low-skill, relative to the uninsured sector.
} 


$$
\begin{gathered}
\frac{p_{i} y_{i}}{p_{0} y_{0}}=\frac{\left(1+\tau_{i L}\right) w L_{i}+\left(1+\tau_{i K}\right) r K_{i}}{\left(1+\tau_{c L}\right) w L_{0}+\left(1+\tau_{c K}\right) r K_{0}} \\
=\frac{L_{i}}{L_{0}} \frac{1+\tau_{i K}}{1+\tau_{c K}} \frac{M R T_{i}+\left(M R T_{i} \frac{1-\alpha_{i}}{\alpha_{i} A_{i}}\right)^{\sigma}}{M R T_{c}+\left(M R T_{c} \frac{1-\alpha_{0}}{\alpha_{0} A_{0}}\right)^{\sigma}}
\end{gathered}
$$

where we assume that the sector 0 has ESI because it has the least administrative costs and the most skill-intensive technology of all sectors. The second equality in (10) is derived from the first by using the MRT condition (7).

The relative production in the two sectors can also be examined on the supply side using the production function:

$$
\frac{y_{i}}{y_{0}}=e^{\delta_{0}-\delta_{i} I N S(i)-[1-I N S(i)] x} \frac{z_{i}}{z_{0}}\left(\frac{\alpha_{i} A_{i}}{\alpha_{0} A_{0}}\right)^{\sigma /(\sigma-1)} \frac{L_{i}}{L_{0}}\left[\frac{M R T_{i}^{\sigma-1}\left(\frac{1-\alpha_{i}}{\alpha_{i} A_{i}}\right)^{\sigma}+1}{M R T_{c}^{\sigma-1}\left(\frac{1-\alpha_{0}}{\alpha_{0} A_{0}}\right)^{\sigma}+1}\right]^{\sigma /(\sigma-1)}
$$

Substituting (10) and (11) into the demand condition (9), we can characterize the allocation of low-skill labor across sectors:

$$
\begin{gathered}
\frac{L_{i}}{L_{0}}= \\
e^{\left(\rho_{i}-\rho_{0}\right) \lambda}\left[e^{\delta_{0}-\chi-\left(\delta_{i}-\chi\right) I N S(i)} \frac{z_{i}}{z_{0}}\left(\frac{\alpha_{i} A_{i}}{\alpha_{0} A_{0}}\right)^{\sigma /(\sigma-1)}\right]^{\lambda-1}\left(\frac{1+\tau_{c L}}{1+\tau_{i L}}\right)^{\lambda}\left[\frac{M R T_{i}^{\sigma-1}\left(\frac{1-\alpha_{i}}{\alpha_{i} A_{i}}\right)^{\sigma}+1}{M R T_{c}^{\sigma-1}\left(\frac{1-\alpha_{0}}{\alpha_{0} A_{0}}\right)^{\sigma}+1}\right]^{(\lambda-\sigma) /(\sigma-1)}
\end{gathered}
$$

Recall that MRT and the tax rates are the same for all sectors with the same insurance offering, so that the low-skill labor allocation across those sectors depends only on the taste and technology parameters indicated in equation (12).

An analytical result is helpful for understanding the quantitative sectoral analysis that follows. 
Proposition Holding aggregate factor supplies constant, sector-neutral subsidies have no effect on the sectoral allocation of factors, the composition of output, or sectors' relative prices.

Proof With sector-neutral subsidies, the cost comparison (6) is merely a comparison of $\delta$ and $\chi$; the ESI and NGI cost functions are the same. Because all sectors have the same marginal rate of transformation (MRT) between the two types of labor, it follows from equation (12) that the allocation of low-skill labor across sectors depends only on the industry profiles for tastes and technology, and the level of $M R T$, but not the level of taxation or the degree to which taxes vary by skill level. This result and the common $M R T$ across sectors imply allocations of highskill labor and output across sectors that depend on tastes, technology, and the level of MRT but not tax rates. An equilibrium level for $M R T$ makes the $K$ profile consistent with the fixed aggregate supply of $K$, but neither of these depends on tax rates. From equation (8), sectors' relative prices depend only on the preferences and the allocation of output. The pattern of tax rates by skill level does affect the relative factor price $w / r$.

\section{Measurement of Tax Wedges and Calibration of Behavioral Response}

\section{Rates}

In order to make quantitative predictions, we begin by measuring the tax wedges created by the ACA. We then assume functional forms for the distribution functions $\delta(i)$ and $\alpha(i)$ and relate their key parameters to quantitative estimates of coverage outcomes and sensitivity of those outcomes to tax rates. We also calibrate the utility and production parameters from the labor economics literature. ACA impacts are found by holding constant the distribution functions, utility parameters, and production parameters and varying the tax parameters from their non-ACA values to their ACA values. Impact sensitivity analysis is performed by varying one of the calibration inputs from the empirical literature while holding the other calibration 
inputs constant, which requires varying one of the taste or technology parameters in order to continue to match the latter calibration inputs. ${ }^{12}$

\section{Functional Forms for Sectoral Taste and Technology Gradients}

We assume that the taste function $\rho(i)$ is quadratic in $i$. We assume that the skill-intensity function $\alpha(i)$ and administrative cost function $\delta(i)$ are linear.

Because the slope of the administrative cost function dictates the propensity of employers to change their ESI-offer decision, we set the slope so that the elasticity of ESI offerings with respect to the price of ESI is $-1 / 3$ in the neighborhood of efficient ESI, assuming that 9 percent of covered employee compensation (plus the implicit tax subsidy) goes to ESI coverage. The calibrated value for the elasticity is based on the same empirical studies reviewed by the Congressional Budget Office (2007), which is why our model's predictions are similar to CBO's if we hold constant the composition of consumer demand.

We set the level of the net administrative cost function $\delta(i)-\chi$, the two parameters for the skill-intensity function $\alpha(i)$, and the two parameters for the taste function $\rho(i)$ so that our model equilibrium without the ACA matches the data on employee compensation by skill level and the composition of the workforce by skill level and ESI coverage, as measured in the March 2012 CPS. $^{13}$

\section{Other Taste and Technology Parameters}

We convert numbers of covered employees into numbers of plan participants (including dependents) by multiplying by 2.0, which is the ratio of ESI plan participants as measured by the Congressional Budget Office (2013) to the number of non-elderly heads and spouses covered by ESI as measured in the March 2012 Current Population Survey.

\footnotetext{
${ }^{12}$ For example, for a sensitivity analysis with respect to the wage elasticity of labor supply $\eta$, we must vary the utility parameters $\gamma_{L}$, and $\gamma_{K}$ together with $\eta$ in order to continue to match data on wage rates and the number of people from the two skill groups who work.

${ }^{13}$ Note that one parameter of the quadratic taste function is irrelevant because it does not affect the relative consumer preference for sectors.
} 
Unel (2010) reviews econometric estimates of the elasticity of substitution in production between high- and low-skill labor ( $\sigma$ in our notation) and reports a range of 1.4 to 1.7 (with some indication that it has increased over time). Acemoglu (2002) reports a wider range of 1 to 2 , which we use because our definition of skill groups is not exactly the same as in the econometric studies. Our benchmark value of $\sigma$ is 1.5 .

Appendix I further discusses the calibration of the taste and technology parameters. Of particular interest for interpreting our results is that all potential workers in our model economy are non-poor (adjusted household income more than $100 \%$ of the federal poverty level), nonelderly household heads and their spouses. Potential workers are quantified according to the aggregate number of non-poor non-elderly household heads and spouses who worked some time during 2011, as measured by the March 2012 Current Population Survey and rescaled to reflect three percent population growth between 2012 and 2015 (that is, 98 million rescaled to 101 million). ${ }^{14}$ Dependents appear in the model only as people who might have health insurance and thereby might affect incentives for the head or spouse in their household to work or change sectors.

Model workers are of only two types, low- and high-skill, which refers to whether husband plus wife personal income (including the value of health insurance premiums, if any, paid by employer) are below or above 300 percent of the federal poverty line, respectively. ${ }^{15} \mathrm{We}$ do not further distinguish workers according to weeks worked or weekly hours, although we do account for these variables by measuring labor compensation according to average earnings for calendar year 2011 (adjusted for inflation between 2011 and 2014), including the value of employer-paid ESI premiums. ${ }^{16}$ Therefore, if our model predicts, for example, that a million low-skill workers move from one sector to another, we interpret that to mean that the one million workers have the same average annual earnings as the other low-skill workers in the economy. ${ }^{17}$

\footnotetext{
14 Three-quarters of aggregate hours were supplied by these 98 million, with the rest supplied by the elderly, the poor, or persons who are not head or spouse.

${ }^{15}$ For unmarried households, head of household personal income is used.

${ }^{16}$ These averages are reported in the middle of Table 6. All dollar amounts in this paper are in 2014 dollars.

${ }^{17}$ Another example: we interpret a one percent reduction in low-skill labor supply to be some combination of reductions in the number of low-skill people working some time during the year and the average annual hours worked among low-skill people; our model is not set up to distinguish the two.
} 


\section{Tax Wedge Measurement}

We model health reform as changes in the tax and subsidy rates $\left\{\tau_{c L}, \tau_{c K}, \tau_{n L}, \tau_{n K}, \tau_{u L}, \tau_{u K}, s_{L}, S_{K}\right\}$, and the labor market consequences of health reform as the equilibrium comparative statics with respect to the tax and subsidy rates. Obviously, the quantitative results hinge on the numerical values assumed for the tax parameters with and without health reform. We calibrate the tax rates so that they reflect the combination of (when applicable) employer payroll taxes, employer penalties, subsidies for purchasing health insurance on the exchanges, employer health insurance participation charges, and the tax exclusion of employer health insurance premiums. In practice, the various tax rate components are treated differently by business and personal income tax rules and are collected on different time scales and therefore need to be rescaled into "common units" before they are added to arrive at a combined tax rate.

In reality, some of the taxes are proportional to payroll expenditure and others are proportional to the number of employees, but for algebraic simplicity we model all of them as skill-specific proportions of payroll. In calibrating the proportions, we must decide whether the various component proportions accumulate additively or multiplicatively. ${ }^{18}$ We assume that the employer FICA and Medicare rates are added with each other because (for employees with earnings below the FICA earnings cap) they are levied on the same base, but that they multiply the value of the tax exclusion for employer health insurance because the latter comes out of the tax base for the former. We assume that the various ACA taxes and subsidies are additive with each other, but multiply the non-ACA tax rates. ${ }^{19}$

In our model, all workers of the same skill level receive the same total compensation regardless of the sector of their employment. All of the sector-specific taxes and subsidies are paid and received by employers. As a normalization that streamlines our notation, we assume that all employees receive a cash subsidy (appropriate to their skill level, but sector neutral) as if they purchased health insurance on the exchanges and then employers in the ESI and uninsured sectors are taxed to finance subsidies received by their employees. This means that the exchange

\footnotetext{
${ }^{18}$ To a first order approximation in the neighborhood of zero tax rates, it does not matter whether the rates add or multiply. However, actual tax rates are far from zero and the second order interaction terms are not negligible.

${ }^{19}$ If the ACA taxes were additive with the value of the employer tax exclusion, then sector-uniform ACA taxes would nonetheless cause substitution between sectors.
} 
subsidies are reflected in $\left\{\tau_{u L}, \tau_{u K}, \tau_{c L}, \tau_{c K}\right\}$ but not $\left\{\tau_{n L}, \tau_{n K}\right\}$. Our normalization is economically equivalent to paying the subsidies only to employees who work in the NGI sectors, but in the latter case the extra employer costs for the ESI and uninsured sectors would be compensating cash payments to employees (for forgoing the exchange subsidies) rather than extra taxes. Because we use the former approach while the actual ACA takes the latter, adjustments to $w$ and $r$ are required before comparing our model to empirical measures of employee compensation.

The monetary penalties on employers who do not offer health insurance to their full-time employees are included in the tax rates $\left\{\tau_{n L}, \tau_{n K}, \tau_{u L}, \tau_{u K}\right\}$ of employers operating in the NGI and uninsured sectors. The individual mandate penalties on uninsured persons are included only in $\left\{\tau_{u L}, \tau_{u K}\right\}$. Finally, the major medical reinsurance assessments are included in the ESI sector tax rates $\left\{\tau_{c L}, \tau_{c K}\right\}$.

The top and middle panels of Table 2 show the annual tax amounts (excluding employer payroll tax) and percentage rates (including employer payroll tax). Absent the ACA, the tax amounts are zero with the exception of the roughly $\$ 2,500$ subsidy for ESI employees implicit in the income and payroll tax exclusion of employer health insurance premiums. The employer tax rate without the ACA (the first two columns in Table 2's middle panel) is the sum of 7.65\% (7.7\% when rounded to the nearest tenth of a percent) and the ratio of the corresponding tax amount to the average total compensation for the skill level. ${ }^{20}$

We calibrate the tax rates with the ACA by building on the without-ACA rates and information about the likely combined ACA tax and subsidy amounts $R$ (see also Table 3 ) for each sector and skill level:

$$
1+\tau_{i L}=\left(1+\bar{\tau}_{i L}\right) \sqrt{\frac{1+R_{i L} / \bar{w}}{1-R_{i L} / \bar{w}}}, \quad 1+\tau_{i K}=\left(1+\bar{\tau}_{i K}\right) \sqrt{\frac{1+R_{i K} / \bar{r}}{1-R_{i K} / \bar{r}}}
$$

\footnotetext{
$207.65 \%$ is the sum of the employer FICA and Medicare tax rates. We use $\$ 32,381$ and $\$ 82,813$ for the (pre-ACA) low- and high-skill total compensation amounts, respectively, which are the average annual earnings for working (some time during 2011) non-elderly household heads and spouses in households that are between 100 and 300 percent of the poverty line, and above 300 percent of the poverty line, respectively.
} 
where the overbars indicate without-ACA values. ${ }^{21}$ Table 2's middle panel rates are used in our market simulation.

The impact of the ACA on employer tax rates is astonishing. Rates increase by a factor of about 1.6 for high-skill employees and many times more for low-skill employees. However, the table omits the sector-neutral employee subsidy noted above, so the most important information in Table 2's middle panel is the degree to which the tax rates vary by sector and skill level and how the ACA changes and amplifies that variation. Among high-skill workers, the ESI sector's advantage over the other sectors goes from 3.1 percentage points to as much as 10.0 percentage points. Among low-skill workers, the ESI advantage goes from 7.5 percentage points to -21.3 (NGI) or 29.1 percentage points (uninsured).

The middle and bottom panels of Table 2 also show how the ACA distorts the sectors' comparative advantage in the labor market. For each pair of sectors $i$ and $j$, the bottom panel uses the tax rates in the middle panel to calculate the ratio of $\left(1+\tau_{i L}\right) /\left(1+\tau_{i K}\right)$ to $\left(1+\tau_{j L}\right) /\left(1+\tau_{j K}\right)$. The ratio indicates how the tax rates distort comparative advantage relative to taxes that were uniform by skill or by sector (zero taxes would be a special case). Without the ACA, there would be no distortion between uninsured and NGI (if there were any NGI). The without-ACA rates distort the composition of uninsured factor demand, relative to the ESI sector, by four percent in the direction of high skill workers because the value of the tax exclusion of ESI premiums is a greater percentage of low-skill ESI employee compensation than it is of high-skill ESI employee compensation. ${ }^{22}$ The ACA slightly magnifies this distortion from 1.04 to 1.11 because the employer penalties for uninsured employees are also a greater percentage of lowskill compensation than of high-skill compensation.

The ACA creates a remarkable 1.38 distortion of comparative factor advantage between the uninsured and NGI sectors. The 1.38 is not a consequence of favoring the NGI sectors over

\footnotetext{
${ }^{21}$ The ACA's penalties and subsidies are usually dollar amounts as opposed to the more analytically convenient percentages of compensation. Moreover, in theory the dollar amounts generated by a given percentage tax rate is an equilibrium outcome because the rate's tax base is an equilibrium outcome. The square root formulas (13) are the geometric average of two approaches to guessing, on the basis of pre-ACA data, the equilibrium tax rate that would deliver a specified amount of revenue: one approach that sets the rate as revenue divided by the pre-ACA marginal revenue product of labor and a second approach that sets the rate as revenue divided by the pre-ACA wage rate. ${ }^{22}$ Recall that Figure 1 offered a first glimpse at this result in its $K / L$ series that jumps up slightly on the margin between ESI and uninsured.
} 
uninsured sectors - presumably the ACA is designed to discourage the uninsured - but is a consequence of failing to favor the NGI sectors in a factor-neutral way.

Table 3 gives more detail behind the tax and subsidy amounts in Table 2 by showing the legislative components, conversion factors, and the sectors to which each component applies. The \$2,660 implicit subsidy amount for a full-year worker was derived by multiplying an estimated annual exclusion amount (\$7,980: see Appendix I) by an assumed combined marginal tax rate from payroll and personal income taxes $(25 \%)$ and dividing by one minus the same marginal tax rate in order to convert it to an equivalent salary increment. ${ }^{23}$ The employer shared responsibility payment is part of the NGI and uninsured annual amounts in Table 2. It is $\$ 2,000$ per full-time employee, which is $\$ 1,656$ per low-skill employee if 83 percent of them work full time. An employer payment of $\$ 1,656$ is not deductible from business taxes and therefore has an employer cost equivalent to a $\$ 2,522$ annual salary increment (when the tax rate on business net income is $39 \%$ ).

With the ACA, ESI employers owe about $\$ 126$ per employee-year as an insurance participation assessment. $^{24}$ The next three rows of Table 3 pertain to the federal subsidies for purchasing insurance on the exchanges, which in our model are paid to all persons but then clawed back from persons without insurance and from persons employed in ESI sectors. The subsidies $-\$ 7,795$ on average for heads and spouses in households below $300 \%$ of the poverty line - are untaxed by personal income and payroll taxes. At a 25 percent combined personal tax rate, the salary equivalent increment is $\$ 10,624 .^{25}$

The next row is the individual mandate penalty. The penalty as of 2016 is 2.5 percent of household income, or $\$ 695$ per uninsured family member (up to three members, with uninsured

\footnotetext{
${ }^{23}$ For example, a person earning $\$ 50,000$ per year with only $\$ 41,000$ taxable would, at a $25 \%$ marginal personal tax rate, have the same income after personal taxes as someone earning $\$ 53,000$ with no exclusion. $\$ 3,000$ is the salary increment equivalent value of the $\$ 9,000$ tax exclusion. The two amounts shown in the upper left of Table 2 are the $\$ 2,660$ adjusted for the average annual weeks worked among non-elderly heads and spouses (by skill level).

${ }^{24}$ The assessment is $\$ 63$ per plan participant, and we assume that each employee with coverage has covered an average of 1.0 dependents $(126=63 * 2)$. Exchange plans also pay the assessment, but the aggregate revenue from the assessment effectively goes to the exchange plans, purportedly to offset losses from admitting participants with pre-existing health conditions (another ACA provision).

${ }^{25}$ The exchange subsidies have dollar amounts that are skill-specific. Table 3 displays only the low-skill average amounts of $\$ 7,968$ and $\$ 10,624$; the high-skill average amounts are $\$ 681$ and $\$ 908$.
} 
children counting half), whichever is greater. The median penalty per dollar of wages for each low-skill working uninsured household head or spouse in the March 2012 CPS was 4.2 percent. $^{26}$

Illegal immigrants are not subject to the individual mandate and cannot purchase plans in the ACA's marketplaces. They are also among the least skilled workers, and many of them work in sectors that are far enough to the right in Figure 2 that they are not on the margin of being insured (either NGI or ESI). Arguably illegal immigrants are not relevant for any of the margins examined in our model, which would mean that our model should be calibrated with the full penalty and subsidy amounts without any discount for the fraction of work that is done by illegal immigrants. As a middle ground, we discount the individual mandate penalty (but not the exchange subsidy, or the employer penalty) among low-skill workers by 20 percent, which is our guess of the fraction of low-skill workers uninsured before the ACA that were illegal immigrants. ${ }^{27}$ When converted to a salary equivalent, the amount is $\$ 1,348$.

The first "TOTAL" row in Table 3 sums the applicable salary equivalent rows above for ESI, NGI, and uninsured sectors. However, these amounts cannot be compared to the wage rate $w$ in our model, which is the average annual compensation of low-skill workers including the weeks of the year (averaging 4.7) that they are not employed. The Table's final row therefore rescales the row above by the average weeks employed per year among low-skill household heads and spouses. ${ }^{28}$ Also note that the bottom total row appropriately quantifies incentives to move employees across sectors: for example, if a low-skill employee were moved from an uninsured sector to the ESI sector, that would not reduce the employer shared responsibility payment by $\$ 2,000$ per year because the uninsured sector employer was paying the assessment only for the part of the year when the employee was on the payroll.

All of the amounts and rates shown in Tables 1-3 assume full implementation in the sense that the ACA is fully enforced, all employers not offering ESI are penalized, and households value the subsidies at the dollar amounts we have assigned to them. However, part of the population may not value the insurance options offered by the insurance exchanges, and

\footnotetext{
${ }^{26}$ For high-skill workers, we assume that the individual mandate penalty is 2.5 percent of household income and convert it to a salary equivalent using the same marginal tax rate factor.

${ }^{27}$ See also our discussion below of the aggregate labor supply distortions.

${ }^{28}$ High-skill persons are employed an average of 49.9 weeks per year.
} 
therefore forgo participation in those plans and forgo the ACA subsidies. ${ }^{29}$ In addition, states may fail to set up insurance exchanges, and perhaps thereby make their residents ineligible for premium support and cost sharing subsidies, even those who comply with the individual mandate (Pear 2012). It is beyond the scope of this paper to explicitly model compliance choices, or even exhaustively catalog all of the possible margins of implementation, take-up, compliance and enforcement that are possible with a significant law that is unpopular with large segments of the population, but we do introduce a penalty "implementation rate" and a subsidy "implementation rate" as model parameters on the unit interval that multiply the tax and subsidy amounts noted above. $^{30}$

\section{The Coverage Decision: Quantitative Results}

Our model has predictions for the effect of the ACA on the amount and composition of insurance coverage. Both predictions utilize pre-ACA measurements of various aspects of insurance coverage, but quantitative results also require functional form assumptions. For predicting ESI coverage, the functional form assumptions serve the purpose of interpolating preACA measurements and in principle would not be necessary if the pre-ACA measurements were sufficiently disaggregated. For predicting the number of people without insurance, functional form assumptions are needed to extrapolate outside the range of historical experience. For these reasons, ESI predictions might be more reliable than the predictions for the number uninsured (although see below on some of the unknown determinants of ESI coverage).

\footnotetext{
${ }^{29}$ Members of Congress are required to obtain their family's health insurance through the exchanges (Pear 2012) - a requirement that we presume was intended to ensure that the exchange plans are desirable to middle-income families - but perhaps we do not fully anticipate the ultimate design of those plans, or the public's perception of their design.

${ }^{30}$ For example, a $50 \%$ subsidy implementation rate means that we calibrate the tax wedges for low-skill workers based on a $\$ 3,984$ average annual subsidy for exchange coverage, rather than the $\$ 7,968$ average we estimated from CPS data on low-skill workers (we do the same procedure for high-skill workers). One interpretation of the 50\% subsidy implementation rate is that workers value the exchange subsidies at only 50 cents per dollar we imputed for them in our CPS averages.
} 


\section{Cost Functions, the Break-Even Test, and Empirical Indicators of the Relative}

\section{Demand for ESI and NGI}

The model's coverage decision involves the choice (6) among three possible cost functions, repeated below for convenience:

$$
-\ln z+\min \left\{\begin{array}{l}
\chi+\frac{1}{1-\sigma} \ln \left[(\alpha A)^{\sigma}\left[\left(1+\tau_{u L}\right) w\right]^{1-\sigma}+(1-\alpha)^{\sigma}\left[\left(1+\tau_{u K}\right) r\right]^{1-\sigma}\right] \\
\delta+\frac{1}{1-\sigma} \ln \left[(\alpha A)^{\sigma}\left[\left(1+\tau_{n L}\right) w\right]^{1-\sigma}+(1-\alpha)^{\sigma}\left[\left(1+\tau_{n K}\right) r\right]^{1-\sigma}\right] \\
\delta+\frac{1}{1-\sigma} \ln \left[(\alpha A)^{\sigma}\left[\left(1+\tau_{c L}\right) w\right]^{1-\sigma}+(1-\alpha)^{\sigma}\left[\left(1+\tau_{c K}\right) r\right]^{1-\sigma}\right]
\end{array}\right\}
$$

Four factors potentially affect equilibrium prevalence of each decision: (a) the distribution of administrative costs $\delta$ net of the disutility $\chi$ of being uninsured, (b) the tax rates, (c) the distribution of the skill-intensity parameter $\alpha$, and (d) the relative factor price $w / r$. However, recall from Table 2 that the tax factor $q_{u c}$ is fairly close to one without the ACA, which means that the log term for ESI coverage differs from the log term for no coverage by essentially the same constant for all sectors so that the distribution of administrative costs is the primary determinant of the margin (if any) between ESI and not insured. As noted above, we calibrate that distribution from the microeconometric literature on the historical sensitivity of ESI offering decisions to the price of ESI.

Absent the ACA, employees find that NGI is strictly dominated by ESI: recall from Table 2 that both skill levels are taxed less under ESI coverage than under NGI coverage. Therefore, marginal changes in any of the four factors (a)-(d) in the neighborhood of the no-ACA allocation have no effect on the model's (zero) prevalence of NGI among employees. For larger changes think of varying the ACA subsidy implementation rate between zero and 100 percent - some of the employers offering ESI absent the ACA find it optimal to offer NGI instead. In this range, the distribution of administrative costs affects the prevalence of ESI only through general equilibrium effects because $\delta$ disappears when equation (6)'s third term is subtracted from its second. What really matters for the decision to replace ESI with NGI is the employer's propensity to use low-skill labor. 
The cost functions (6) highlight the importance of skill intensity as a determinant of the type of coverage, conditional on having private coverage. Holding $w / r$ constant and assuming that $\sigma>1$, an employer achieves minimum cost by replacing ESI with NGI if and only his ACAabsent compensation ratio satisfies:

$$
\frac{\left(1+\bar{\tau}_{c L}\right) w L_{i}}{\left(1+\bar{\tau}_{c K}\right) r K_{i}} \geq \frac{1-\left(\frac{1+\tau_{c K}}{1+\tau_{n K}}\right)^{\sigma-1}}{\left(\frac{1+\tau_{c K}}{1+\tau_{n L}} \frac{1+\bar{\tau}_{c L}}{1+\bar{\tau}_{c K}}\right)^{\sigma-1}-\left(\frac{1+\tau_{c K}}{1+\tau_{c L}} \frac{1+\bar{\tau}_{c L}}{1+\bar{\tau}_{c K}}\right)^{\sigma-1}}
$$

where bars indicate the ACA-absent tax rate values. The critical compensation ratio on the righthand side of the inequality (14) is just a function of the tax parameters and the elasticity $\sigma$ of factor substitution. For our baseline tax calibration and $\sigma=1.5$, the critical ratio is 0.32 , which means that any ESI employer with pre-ACA low-skill compensation that is at least 32 percent of its high skill compensation would reduce costs by replacing ESI with NGI. ${ }^{31}$

As $\sigma$ approaches zero, equation (14) reduces to the break-even or "money's worth" test (Rennane and Steuerle 2011) that compares the aggregate subsidy net of penalties received by a firm and its employees if it had NGI coverage rather than ESI to the value of ESI's tax exclusion (aggregated for all employees of the firm):

$$
\lim _{\sigma \rightarrow 0} \frac{1-\left(\frac{1+\tau_{c K}}{1+\tau_{n K}}\right)^{\sigma-1}}{\left(\frac{1+\tau_{c K}}{1+\tau_{n L}} \frac{1+\bar{\tau}_{c L}}{1+\bar{\tau}_{c K}}\right)^{\sigma-1}-\left(\frac{1+\tau_{c K}}{1+\tau_{c L}} \frac{1+\bar{\tau}_{c L}}{1+\bar{\tau}_{c K}}\right)^{\sigma-1}}=\frac{1+\bar{\tau}_{c L}}{1+\bar{\tau}_{c K}} \frac{\tau_{n K}-\tau_{c K}}{\tau_{c L}-\tau_{n L}}
$$

In other words, the break-even test is equivalent to a comparison of the pre-ACA compensation ratio (the left-hand side of inequality (14)) to the right-hand side of equation (15). As long as $\sigma$ $>0$, employers are expected to adjust the composition of their workforce according to the skill

\footnotetext{
${ }^{31}$ For this purpose, and as indicated in equation (14), compensation includes employer payroll taxes and net of the subsidy implicit in the exclusion of health insurance premiums from the personal and payroll tax bases. The critical ratio also depends somewhat on the elasticity $\sigma$ of factor substitution, ranging from 0.29 to 0.36 as $\sigma$ ranges from 1 to 2 .
} 
gradient of employer costs, and the break-even test is only a rough indicator of which insurance offering will minimize employer costs under the ACA. For example, some of the employers in our model (those with pre-ACA compensation ratios between 0.24 and 0.29) retain ESI even though the break-even test conducted before the ACA would suggest that they had enough lowskill employees to gain from dropping ESI because the incentives created by the ACA made it too expensive to retain so many low-skill employees. ${ }^{32}$

Aside from quantifying the tax rates, the essential quantitative determinant of our prediction for the prevalence of ESI under the ACA is the fraction of ESI employers for whom the compensation ratio was at least 0.32 (equivalently, a log ratio of -1.13). Figure 3 illustrates why we think a large minority of ESI employers might reduce costs by switching from ESI to NGI under the ACA. The horizontal axis orders employees according to their employers' preACA cost of ESI relative to no insurance. A vertical line is drawn at workforce quantile 0.79 because $79 \%$ of the workforce (of non-poor household heads and spouses) had ESI before the ACA. Dashed horizontal lines in the chart indicate the log average compensation ratio for ESI employers (-2.03) and non-ESI employers (-0.36). We do not have employer-level data and therefore cannot graph the exact empirical distribution, but we know that it has to match the two conditional averages shown.

The solid curve is the distribution of pre-ACA compensation ratios in our baseline parameterization, which fits the two conditional averages by construction and assumes that $\alpha(i)$ is linear in the quantile $i$. Because the ACA critical compensation ratio shown as a solid horizontal line crosses this curve at quantile 0.73 , we predict that (holding constant $w / r$ and the distribution of employment across sectors) the ACA would reduce the ESI coverage rate from 0.79 to 0.73 . Alternative shaped compensation distributions would result in somewhat different quantitative results. ${ }^{33}$

\footnotetext{
${ }^{32}$ All of the employers in our model (100 percent implementation) who drop ESI pass the break-even test (conducted before the ACA) by a non-trivial margin: about $\$ 1,000$ per employee-year.

${ }^{33}$ It is theoretically possible that most employers have essentially the same skill intensity parameter $\alpha$ and that the ESI average of 0.25 is due to the extreme skill-intensities of employers far from the margin between ESI and no insurance, in which case the ACA could cause essentially all employers to replace ESI with NGI. The other extreme is also theoretically possible: that the $\alpha$ distribution is a step function, with the step coincidentally at the employer on the margin between ESI and no insurance, in which the ACA has no effect on ESI coverage holding $w / r$ constant.
} 
To the degree that employers can avoid the ACA penalties levied on them for not offering health insurance - perhaps by designating their employees as part-time, keeping fewer than 50 full-time equivalent employees, challenging the penalty in court, or obtaining a waiver the critical ratio drops sharply. For example, at half of the penalty the critical ratio drops from 0.32 to 0.18 . Note that the average compensation ratio among employers with ESI before the $\mathrm{ACA}$ is 0.13 , which means that a half penalty might induce many more ESI employers to drop their coverage.

\section{Quantitative Estimates of the ACA's Impact on ESI Coverage}

Figure 4 displays our model's predictions for the change in the number of persons on ESI (including dependents) as a function of the rate at which the penalties and subsidies are implemented. As long as the subsidy implementation rate is no greater than 0.6, ESI continues to dominate NGI under the ACA and ESI participation remains at or somewhat above where it was before the ACA. In these cases, the only people getting the NGI subsidy are those who get insurance on the exchanges after leaving a job with ESI. The magnitude of the ESI impact is composed of two opposing effects: the tendency for the employer and individual penalties to expand the number and size of ESI sectors for a fixed labor supply and the reduction in overall employment due to the additional assistance given to people while they are not working in the form of NGI subsidies. The latter effect dominates only when the penalty implementation rate is low enough and/or the wage elasticity of labor supply is high enough.

Recall from Table 3 that we estimate the average fully-implemented subsidy for low-skill workers to be $\$ 7,968$ per year working in a NGI sector. If that average subsidy were perceived to be worth $\$ 4,800$ or less to the participants - perhaps because NGI participation is significantly more costly in terms of inconvenience, red tape, switching costs, or perceived value deficiencies - then the applicable parts of Figure 4 are those with subsidy implementation rates at or below 0.6 and we conclude that the ACA might not significantly reduce ESI participation. ${ }^{34}$ However, because the law is currently written with Congressmen and their staffs required to get their health

\footnotetext{
${ }^{34}$ This particular conclusion depends on our assumption that ESI cannot be offered to high-skill employees in a sector without also offering it to low-skill employees. As explained in our Appendix III, the ACA might still significantly reduce ESI participation without any sector dropping coverage if employers "window dress" their benefit offerings in order to exploit possible loopholes in the exchange subsidy eligibility rules.
} 
insurance on the exchanges, a cap on participant costs for those under 400 percent of the poverty line, and a large advertising campaign for promoting the exchange plans and keeping them distinct from anti-poverty health programs like Medicaid, our humble guess is that NGI subsidy take-up rates will be high within a few years and that actual behavior will be better represented in our model by a subsidy implementation rate that exceeds $0.6 .^{35}$

With subsidy implementation rates above 0.6 , the ACA can easily reduce ESI participation by ten million or more, although the impact is sensitive to the implementation rate for employer penalties. In our model, a fully-implemented penalty means that it is paid on all full-time employees without health insurance, but the actual ACA does not levy the penalties on employers with fewer than 50 employees, which collectively employ about half of employees without health insurance (Congressional Budget Office 2007). Thus, for purposes of quantifying coverage decisions, the half penalty case is arguably more interesting. If the subsidy implementation rate were 80 percent or so, our model predicts that ESI enrollment (including dependents) could be 20 million less than it would be without the ACA. Just as interesting, the ESI impact is highly sensitive to the subsidy implementation rate over this range and, as we explain further below, how the subsidy is implemented.

The Congressional Budget Office (2013) estimates the ACA's ESI impact by assuming that the variables affecting the ESI-NGI margin are analogous to the variables affecting the ESIno insurance margin, which have been examined by previous empirical studies. But, given that the uninsured far outnumbered those with NGI among non-elderly workers before the ACA, many fewer people may have been on the ESI-NGI margin than on the ESI-uninsured margin. If the ACA introduced only a small subsidy for NGI, then subsidies might have essentially no effect on ESI prevalence, as we find in our model for subsidy implementation rates less than 0.6 (see Figure 4). ${ }^{36}$

\footnotetext{
${ }^{35} \mathrm{We}$ also note that essentially the entire elderly population was enrolled in Medicare within one year of its creation (Carter, et al. 2013, series BD330). On the other hand, some of the state governments may have the ability and desire to block implementation of the ACA. Perhaps those states will behave more like our model with subsidy implementation rates below 0.6 than our model with high subsidy implementation rates.

${ }^{36}$ The nonlinearity of the response of ESI to the exchange subsidies suggests that stigma, quality perceptions, state government interference, or some other barrier that significantly discourages subsidy take-up could have surprisingly large effects on ESI. Perhaps this helps explain why Massachusetts' 2006 health reform, which offered subsidized care to a smaller segment of the population and even then did so by expanding the scope of its Medicaid program, resulted in surprisingly little (if any) reduction in ESI coverage.
} 
Even when the subsidy implementation rate exceeds 0.6, our model of ESI prevalence is radically different from CBO's. In this range, shifts between ESI and NGI have little to do with worker desires to avoid being uninsured, because they are insured either way. ${ }^{37}$ As noted in connection with Figure 3 and in the break-even literature cited above, employer offering decisions are about the composition of their workforce especially as measured by the amount of the subsidy the average employee would get on the ACA's exchanges. Moreover, our approach adds labor supply, output-substitution, and factor-substitution effects to the breakeven calculus: households change the sectors to which they allocate their time and purchases and businesses change the composition of their factor demand.

For penalty and subsidy implementation rates of 50 and 80 percent, respectively, Figure 5 decomposes the ESI impacts into the three "behavioral" components, using the methodology shown in Appendix II. The full effect is the sum of the effects shown in the Figure, plus the effects of employer-level coverage decisions. Factor-substitution adds about one million people (including dependents) to NGI: sectors with NGI increase the low-skill intensity of their workforce while the sectors that retain ESI do the opposite, which by itself moves employees from ESI to NGI sectors even without moving output across sectors. By offering subsidized health coverage to people not working full-time, the ACA reduces aggregate hours worked, in part by moving workers out of ESI jobs into non-employment or part-time work with NGI, and thereby moving about three million ESI participants to exchange plans.

The ACA raises costs for the sectors that didn't have coverage before the ACA (see also Figure 2), which they pay in some combination of insurance administrative costs, employer penalties, and individual mandate penalties. The extra costs are passed on to consumers who shift their demand toward the ESI sectors, which is why the output-substitution effects shown in Figure 5 are positive for ESI and private coverage. The positive output substitution effect on private coverage (equivalently, the negative output-substitution effect on the uninsured sectors) may be an intended effect because a goal of the ACA is to expand coverage by penalizing noncoverage and subsidizing coverage. As we show below, the output substitution effect has

\footnotetext{
${ }^{37}$ There is a small range of subsidy implementation rates near 0.6 for which the ACA both puts workers on NGI and induces a group of employers to offer ESI; the latter occurs to avoid individual and employer mandate penalties.
} 
relatively little effect on output or productivity, whereas the other - perhaps unintended - effects in Figure 5 do.

The NGI sectors experience two output-substitution effects: one because they have higher costs relative to the ESI sectors, but a second in the opposite direction because they have lower costs relative to the sectors that remain uninsured. The net output-substitution effect for the NGI sectors is small and in the direction of increasing their output share.

Figure 5 shows that, overall, more than four million additional exchange participants come from the reallocation of labor among sectors (including the not-employed sector) in response to sector- and skill-specific ACA taxes and subsidies. Our accounting for behavioral changes is the an important reason why we conclude that the exchange plans could ultimately have 30-40 million participants rather than the 25 million predicted by CBO (2013).

Because ESI may primarily compete with NGI under the ACA, it is possible that the individual mandate - the requirement that uninsured persons pay a tax - has little effect on ESI. The individual mandate penalty encourages employers to offer ESI only in the part of the parameter space in which ESI dominates NGI so that ESI competes with uninsured status. In that case, Figure 4 shows that the ACA increases ESI participation by about 10 million (half penalty case).

\section{ESI Coverage by Industry and State}

Our equilibrium model has a continuum of sectors that differ in the skill-intensity of their technology and thereby differ in terms of their compensation ratios absent the ACA, but otherwise the sectors are not readily identifiable as, say, "home construction in the Southwest" or "hospitals in New England." The CPS data helps bridge this gap, and to estimate which industries and regions will disproportionately experience the various labor market changes created by the ACA. By naming some of the sectors in our model, we can generate additional testable implications and obtain a fuller set of incidence results.

We cannot know for sure the skill-intensity of a CPS respondent's employer because the data does not have employer identifiers. We do have state and industry indicators, so we 
estimate low-skill-intensity of a respondent's employer as the fitted value from a regression in the March 2012 CPS sample of non-elderly household heads and spouses (employed sometime during 2011) of a below-300-percent-FPL indicator on indicator variables for state of residence and three-digit industry. Among the industries employing at least 0.5 percent of working nonelderly household heads and spouses (about 400 respondents in the March CPS; 54 civilian industries satisfy this criterion), the top half of Table 4 lists the top and bottom five industries in terms of propensity of its workers to be in households below 300 percent FPL. The bottom of the table lists the top and bottom five states. Also listed in the table is the fraction of the subsample (state or industry) with ESI in their own name as of March 2012.

Workers in some of the most low-skill intensive industries are not especially likely to lose ESI coverage because, as Table 4 shows, ESI coverage was already rare before the ACA. Restaurants, for example, have more than 70 percent of its workers from households below 300 percent FPL, but only 24 percent of its workers have ESI from their employer.

Table 5's first panel shows the top 5 industries in terms of the propensity of full-time time workers to lose ESI as a consequence of the ACA. The propensity is one for a full-time ESI employee with his estimated employer low-skill share of wages above the critical threshold that equalizes the subsidies for exchange plans and ESI and zero for all other workers. ${ }^{38}$ Department and discount stores and traveler accommodation are at the top because ESI was common there before the ACA, but nonetheless a majority of their employees are below 300 percent of the poverty line.

The rest of Table 5 shows the rankings by state. States are less heterogeneous than industries, so the propensity ranges only from 0.04 to 0.23 across states. The top four states in terms of propensity are also the same top four states in terms of prevalence of below 300 percent FPL workers.

With full implementation of penalties and subsidies, our model predicts that 5.8 percent of all workers and 7.4 percent of ESI workers are (without the ACA) at employers that, holding

\footnotetext{
${ }^{38}$ The low-skill share of wages is estimated as the product of the low-skill intensity variable noted above and 0.391 , which is the relative low-skill earnings we use in our model. Overall, most industries are assigned a zero propensity because too few of their workers are below 300 percent FPL.
} 
factor prices constant, would drop their ESI offering as a consequence of the ACA. ${ }^{39}$ Those employees are in workforce quantiles $0.73-0.79$ in Figure 3. According to the model, none of the employees in quantiles 0.80-1 can lose ESI because they do not have it without the ACA. However, the data show that 9 percent of ESI workers are in industries and regions that are quite low-skill intensive - to the right of Figure 3's vertical band where, according to the model, no one has ESI. Their employers are especially likely to drop their health plans because of the exceptionally high fraction of their workers who would be eligible for significant exchange subsidies. Because our model assumes that none of the most low-skill-intensive employers have ESI without the ACA, we expect that our model somewhat underestimates the tendency of the ACA to cause employers to drop their coverage.

A thorough industry or regional analysis would use firm-level data and look at more skill categories, and is beyond the scope of this paper. But Table 5 helps make our model's sectors more concrete, and thereby gives the reader a good idea of where the economic forces emphasized in our paper will be strongest.

\section{Quantitative Estimates of the ACA's Impact on Overall Coverage}

The ACA also helps NGI compete with the no-insurance option. Without the ACA, persons without insurance forgo tax savings equivalent to a reduction in their salary of about $\$ 2,700$ (this does not include administrative costs). Under the ACA, low-skill persons without insurance would forgo a subsidy (net of the employer penalty) of about $\$ 8,000$ and high-skill persons would incur a net penalty of more than $\$ 7,600$ relative to their next best alternative (ESI).

This large change is outside the range examined by the previous literature on the sensitivity of coverage decisions to the cost of insurance, but if we were using a constant elasticity of insurance coverage with respect to the non-administrative cost of insurance (a

\footnotetext{
${ }^{39}$ Our model also predicts that factor prices change, which induces employers to change the skill composition of their workforce and thereby cause still more of them to drop their ESI offering. Moreover, people move off ESI on the model by switching sector of employment. But we point to the 5.8 percent result as one that can be readily compared with cross-sectional models that do not account for the full range of labor market behavioral changes.
} 
functional form sometimes used in that literature), we would predict that the ACA would essentially eliminate the uninsured option. We use the more conservative linear functional form for administrative costs noted above, so that each dollar of savings increases coverage by approximately the same number of participants. Either way, this is an exercise in extrapolation, unlike our interpolative analysis of ESI impact discussed in the context of Figure 3.

The stated goal of the ACA is to reduce the fraction of the population without health insurance, and primarily intends to do so by getting more people to participate in private plans. Figure 6 displays the impact of the ACA on private insurance coverage (ESI and NGI combined). Our benchmark parameterization with $80 \%$ subsidy implementation and 50\% penalty implementation implies that the ACA ultimately increases the number of people with private coverage by 15 million, which is two million more than the CBO's estimate (Congressional Budget Office 2013) and on the high end of the five studies surveyed by Buchmueller, Carey and Levy (2013).

However, the overall coverage impact hinges critically on the degree to which subsidies and penalties are implemented. At a 50 percent penalty implementation rate, the impact on private coverage ranges from 9 to 22 million. The exchange subsidies do not really matter in the range in which ESI dominates NGI because the no-insurance option doesn't compete with NGI in that case. What really matters in this range are the individual and employer penalties from which the ESI sector is exempt: ${ }^{40}$ note the wide gap between the red and blue curves in Figure 6 for subsidy implementation rates at or below 0.5 .

Over the range of subsidies that are valued enough that NGI can compete with ESI, the employer penalties hardly matter for getting people insured because the no-insurance option competes with NGI, both of which create employer penalties. In other words, in order to achieve the goal of reducing the fraction of the population without health insurance, either the NGI plans must be perceived as valuable, or the employer penalties must be enforced. With "success" on the former, employer penalties would not be necessary for expanding coverage. The full penalty green line increases coverage by 18 million even with almost no employer subsides.

\footnotetext{
${ }^{40}$ See the Appendix III for a caveat on the exemption.
} 
Alternatively, the no penalty blue line increases coverage by the same amount with full implementation of employer subsidies.

\section{Conclusions}

A previous literature has noted the ACA's creation of remarkable incentives to change behavior among a variety of labor market participants. This paper takes a couple of next steps, one of which is to systematically quantify the incentives in a common metric of "tax wedges" that recognizes interactions between ACA provisions and pre-existing tax laws. For low-skill workers, a fully implemented ACA's tax wedges would be about the same as tripling employer payroll tax rates. The wedges also vary by sector and skill type, with some sectors and skill types being implicitly taxed dozens of percentage points (of payroll) more than others. The ACA encourages workers to be insured, but not in a factor-neutral way.

Economists cannot reasonably conclude that consumers, employers, and employees would all continue their prior behavior in the face of such large new tax wedges. This paper therefore builds a model of the labor market that is rich enough to explicitly and quantitatively represent a number of the major provisions in the Affordable Care Act, such as the shared responsibility penalties and the subsidies for making purchases on the Act's "health insurance exchanges." The model allows, in response to the new terms of trade in goods and factor markets, employers to change the quantity and composition of their employment and fringe benefits, employees to change sectors (or not work at all) in order to obtain the maximum return on their labor hours, and consumers to change the amount and composition of their purchases.

Because of the various political, legal, and economic challenges to implementing the law, the body of our paper displays a range of results according to the degree (ranging from 0 to 100 percent) to which the ACA's subsidies and taxes are implemented. For the purposes of forecasting behavioral responses, our preferred long-run subsidy implementation rate (if we have a preferred rate: see below) is about 80 percent. Our preferred rate is greater than 50 percent because the exchanges are intended as places where well-to-do people, such as United States Senators, would be able to purchase health insurance that was to their liking, while at the same 
time the subsidies received by households can be applied toward any plan sold in the exchanges. ${ }^{41}$ On the other hand, our preferred rate is less than one hundred percent because it is likely that political uncertainty, equivocal consumer perceptions, bureaucracy costs, product differentiation, and other factors act as a bit of a barrier between exchange plans and employer sponsored insurance. ${ }^{42}$ The size of this barrier will likely vary across states, because insurance plans are regulated by states. The barrier may also change over time as information disseminates, the technology "glitches" are solved, and regulators at both the state and federal levels react to political and budget pressures.

Figure 7 displays the likely range of the ACA's national coverage impacts, assuming half penalty. It is possible that the law increases ESI participation, but in that case our estimate of the number of people moved from uninsured to private coverage (the sum of ESI and NGI coverage) is at the low end: about 9 million. If the exchange subsidies are perceived to be valuable, then we expect the ACA to expand private coverage by 15 million or more, but in the process to reduce ESI coverage by more than 20 million. Another important determinant of the ACA's impact on ESI is the degree, if any, to which ESI participants can work for the same employer as workers receiving the ACA subsidies. By 2016, we expect to have enough data on exchange plan participation that we can calibrate the implementation rates to measures of take-up, participation, and compliance, rather than offering a range of educated guesses as we do now.

Even if every single employer retained its current health insurance offering, behavioral changes could add about 18 million participants to the new exchange plans as employers pass on costs to their customers and change the size and composition of their workforce, and individuals react to the penalty for being uninsured.

Our analysis also helps reconcile the literature's apparently disparate approaches for understanding the consequences of the ACA for ESI coverage. If the exchange subsidies were perceived to be small enough, we predict that the ACA would increase ESI coverage due to the

\footnotetext{
${ }^{41}$ Also note that employer insurance itself is beginning to look more like the ACA's exchanges, as employers join "private exchanges" in order to encourage employees to shop for doctors and hospitals (Hancock 2013) (Murphy 2013).

${ }^{42}$ Pear (2013) gives examples of insurers whose plans on the exchanges offer narrower provider networks than the plans they offer through employers, and examples of exchange plans that exclude major medical centers. See also Terhune (2013) and PricewaterhouseCoopers (2013). It is possible that narrow provider networks would increase exchange participation, rather than decrease it, by giving healthy persons an opportunity to buy relatively inexpensive coverage (Mathews 2013).
} 
individual and employer penalties, which would agree with those who conclude that nationwide ESI coverage will react to the ACA much the same way that statewide coverage reacted to Massachusetts 2006 health reform. ${ }^{43}$ Ignoring the behavioral effects, this parameterization of our model also has some common features with the CBO's (2013) assumption - implicit in their use of historical estimates of the "demand for" ESI - that the primary alternative to ESI for employees at marginal firms is no private insurance. When the subsidies are valued by eligible families closer to their cost to the treasury, an employer's decision to keep or drop coverage is (holding factor prices constant) entirely about the skill intensity of his production technology and has little to do with his employees' preferences to be insured because under the ACA they will be insured either way. ${ }^{44}$

This paper does not attempt to model all of the possible labor market loopholes involved with implementing the ACA. We are examining them in forthcoming research, and for now offer an Appendix III that explains why loopholes may narrow the range of coverage outcomes shown in Figure 7, and make it less likely that the ACA's ultimate impact on ESI coverage could be positive. Appendix III also explains how a number of other results shown in this paper might still be found in a model that featured additional loopholes.

More work is needed to fully understand the sectoral effects of the ACA. This paper does not give any details about the law's Medicaid expansions; our model just aggregates Medicaid participants with all other people lacking private health insurance. We do not give special attention to the health and insurance sectors, but the ACA also changes the way those sectors do business while shifting consumer demand toward them and away from the rest of the economy. Our model does not have any elderly workers, or workers who are not heads (or spouses) of their own household. Such workers supply less than a quarter of aggregate hours, but their supply is still not negligible.

Physical capital is only implicit in our model, which assumes constant returns to the two types of labor. Our results should therefore be interpreted as long-run results: measures of the

\footnotetext{
${ }^{43}$ See Dubay, Long and Lawton (2012) and Gruber (2011).

${ }^{44}$ This is essentially the approach of the money's worth calculations by Rennane and Steuerle (2011) and others that suggest that ESI participation could drop sharply as a consequence of the ACA.
} 
behavioral changes that would occur in the long run in response to a permanent change in the various tax rates.

Our model features heterogeneous sectors, some of which can be interpreted as "entrepreneurial" or intensive in small establishments, and expand as a consequence of the ACA. However, we do not model the ACA's significant employer-size provisions in any detail. Our paper does not specifically model health outcomes, which may well improve enough to compensate for the labor market costs that we do model. Nevertheless, our model provides a framework for understanding the quantitative implications of several of the more important provisions of the ACA and their long-run impacts on a heterogeneous and flexible labor market.

\section{Appendix I: Model Calibration}

Table 6 displays our benchmark model parameters. ${ }^{45}$ The baseline factor allocation refers to millions of non-poor non-elderly household heads and spouses represented in the March 2012 CPS who worked some time during calendar year 2011, and then rescaled by a factor of 1.03 to account for population growth between 2012 and 2015. They total 101 million. A worker is considered "with ESI" if he or she is covered by ESI, even if a family member is the policy holder. Tax rates are measured accordingly (see Tables 2 and 3). For example, the average ESI subsidy implicit in the exclusion of ESI premiums from payroll and income tax bases is based on the average ESI premiums $(\$ 7,980$, regardless of whether they are "paid by" employer or employee) among employees with ESI. We count zeros in that average for employees that obtain their ESI through a family member.

Note that illegal immigrants are represented by our calibration, to the extent that illegal immigrants are detected by the CPS and are above the poverty line. Part-time workers, some of which have ESI, are also included, although they are a small minority of working non-poor nonelderly heads and spouses (even low-skilled workers without ESI are 83 percent full-time).

\footnotetext{
45 "Benchmark" refers to our preferred or focal parameter vector. "Baseline" refers to economic outcomes without the ACA, which we associate with economic outcomes before January 2014 when the premium subsidies go into effect.
} 
However, conditional on skill and ESI, part-time workers are not modeled separately from fulltime workers, which means that our calibrated model cannot account for the possibility that the incidence of part-time work for sectors on the margin of ESI might be different from the population average. We do have endogenous labor supply, and some of that response can be interpreted as movements of workers between full- and part-time status, but we cannot decompose the labor supply response between weekly hours and other margins.

We estimate ESI premiums and hypothetical NGI premiums using the Kaiser Foundation's silver plan premium calculator (hereafter, "KFF calculator") for calendar year 2014. The calculator reports, among other things, the full cost premium (that is, with no premium assistance) for individuals on the basis of their age. We convert the premium into "expected" (in the actuarial sense) medical expenses by dividing by 0.7 . We sum the expected medical expenses across family members who participate in an actual ESI plan or would, under the ACA, hypothetically participate in an NGI plan. The ESI premium is assumed to be 83 percent of expected medical expenses, with the other $17 \%$ covered by various forms of out-ofpocket payments (Gabel, et al. 2012). The NGI premium (without subsidies) is assumed to be 70 percent of expected medical expenses.

The hypothetical NGI subsidy is zero if family income (including the cash value of employer ESI contributions) is outside the range for which premiums are capped by the ACA, or if the caps for premiums and out-of-pocket costs exceed the expected medical expenses themselves. The subsidy is also zero for a married person with an ESI-worker spouse because that person can leave or enter the NGI sector with no consequences for the family's exchange subsidy because the spouse's job and the ACA's so-called "family glitch" by themselves render the entire family ineligible for exchange subsidies. ${ }^{46}$ Otherwise, the subsidy relevant for an earner's decision to work in one sector or another is the difference between expected family medical expenses and the applicable cap based on family income. ${ }^{47}$

Our model's employer taxes by themselves create a significant wedge between labor supply and labor demand. Because the employee-weighted average of the full-implementation

\footnotetext{
${ }^{46}$ See also Burkhauser, Lyons and Simon (2011).

${ }^{47}$ Note that, for the purposes of calculating wedges between sectors, the family subsidy is counted twice for dualuninsured-worker couples and counted zero for dual-ESI-worker couples because either spouse can unilaterally render the family ineligible for exchange subsidies by taking an ESI job.
} 
tax rates are close to the ACA overall average impact of 4.9 percentage points reported in Mulligan's (2013) study of marginal labor income tax rates (assuming somewhat less than full implementation), we do not model any additional ACA impact on after-tax shares and therefore calibrate $s_{L}$ and $s_{K}$ as 0.50 and 0.44 , respectively, regardless of the presence of the ACA. ${ }^{48}$

\footnotetext{
${ }^{48}$ Because neither of these calculations account for illegal immigrants, the aggregate and skill-specific labor supply results are best understood as predictions for the legally resident (non-poor) population.
} 


\section{Appendix II: Decomposing ACA Impacts into Behavioral Components}

Our model has several types of decisions by employers, employees, and consumers. Aggregate labor supply decisions can be isolated by comparing the model with a positive wage elasticity of labor supply to the otherwise identical model with inelastic labor supply. Sectoral shifts in consumer demand by sector can be isolated by comparing the model with a positive substitution elasticity in consumer preferences to the otherwise identical model with Leontief consumer preferences. We isolate employer decisions to drop ESI by comparing our equilibrium model with a variant of the model that requires each sector to have the same ESI offering under the ACA as they have in the equilibrium model without the ACA. ${ }^{49}$

Among these three behaviors, we can shut down any of the three, or all three at a time, or none. Because the behaviors interact with each other, this makes four ways to calculate the impact of any one of the behaviors; we take the average of the four. ${ }^{50}$

When the model has inelastic labor supply, Leontief consumer preferences, and fixed ESI offerings, the ACA's impact on coverage and other variables are the combination of two additional forms of behavior: factor-substitution effects and the decision to be uninsured. In order to isolate the factor-substitution effect on employment or any other outcome, we take each sector and calculate what its outcome would be under the ACA if it changed its factor ratio to coincide with its non-ACA factor mix, holding constant its employee compensation $(w L+r K$, evaluated at ACA factor prices). We do the same by achieving the non-ACA factor ratio with the ACA wage bill, and average the two results (the two components in the average are essentially the same). Factor substitution effects are summed across groups of sectors to get aggregate factor substitution effects for the group, using weights when appropriate.

For example, if employment is the outcome, sector $i$ 's factor substitution effect is:

\footnotetext{
${ }^{49}$ That is, we take the no-ACA equilibrium sectoral profile for $E S I(i)$ and calculate an ACA equilibrium that imposes $\operatorname{ESI}(i)$ on employers. Those sectors that have $\operatorname{ESI}(i)=0$ choose NGI or uninsured status in order to minimize their cost.

${ }^{50}$ For example, to calculate the aggregate labor supply component of, say, the ESI coverage impact, we compare a model with inelastic labor supply to an otherwise equivalent model with elastic labor supply. The two models being compared can both have Leontief consumer preferences, or both impose the non-ACA ESI $(i)$ profile, or both have Leontief preferences and impose a profile, or both have endogenous sectors and endogenous ESI. In practice, the four approaches yield similar quantitative estimates.
} 


$$
\begin{aligned}
& \left(K_{i}^{\prime}+L_{i}^{\prime}\right) \frac{1+R_{i}^{-1}}{2}-\left(K_{i}+L_{i}\right) \frac{1+R_{i}^{\prime}}{2} \\
& R_{i} \equiv \frac{w L_{i}^{\prime}+r K_{i}^{\prime}}{w L_{i}+r K_{i}}, \quad R_{i}^{\prime} \equiv \frac{w^{\prime} L_{i}^{\prime}+r^{\prime} K_{i}^{\prime}}{w^{\prime} L_{i}+r^{\prime} K_{i}}
\end{aligned}
$$

where primes ( ) indicate outcomes with the ACA and no prime indicates no-ACA outcomes. The factor substitution effect on, say, ESI coverage is the sum of the factor substitution effect of each ESI sector, rescaled to convert from employment to plan participants. 


\section{Appendix III: The Window-dressing Margin and ESI participation}

In the main text, we assume than any employee's receipt of ESI renders all workers in his sector ineligible for exchange subsidies. At least five possible loopholes might allow some workers in a sector to receive ESI while others receive exchange subsidies: the legal boundaries of businesses could change so that low- and high-skill workers in the same sector are legally more segregated than they were before the ACA, selected full-time employees could have their hours reduced enough to make them ineligible for ESI, employers could tweak their health plan offerings so that federal regulators deem them unaffordable or insufficient, new employees could be put on occupation-specific orientation periods, and former employees who normally participate in ESI (especially retirees and the unemployed using COBRA) could be given the option to use the exchanges instead. The purpose of this appendix is to explain how these forms of window dressing can be included in our framework, the possible extent of window dressing, and how window dressing changes our results.

Burkhauser, Lyons and Simon (2011) found that a little window dressing can go a long way toward making middle- and low- income people eligible for exchange subsidies without any real change in their employment situation, tax situation, or benefits package. In particular, if employers were to re-label their single-coverage plan or plans so that 100 percent of the premium was paid by the employee (employees could be kept whole with a minor raise in their cash compensation - but see below), then 6 percent of employees currently with ESI - about one fifth of low-skill employees currently with ESI - would be deemed as having no affordable ESI option and could thereby receive exchange subsidies while the rest of their coworkers continued with their ESI. The subsidy would far exceed the $\$ 3,000$ employer-penalty triggered by their exchange participation.

Another possible tweak to benefit offerings would be to reduce the fraction of employee health care costs that are covered by the offered plans below 60 percent, so that the ACA deems the ESI as not comprehensive enough. ${ }^{51}$ This is not pure window dressing, because affected high-skill employees would have to pay more out-of-pocket, but it might be minor compared to the other behavioral changes we consider in this paper.

\footnotetext{
${ }^{51}$ We are not sure whether it would be sufficient to make this adjustment to single-coverage plans, or whether it would have to be made to all plans offered by the employer.
} 
In order to model these possibilities, we introduce a window-dressing parameter that indicates the fraction of low-skill employees in ESI sectors who are eligible for exchange subsidies. That parameter affects our model simulation in only two ways. First, it affects our calibration of the tax rate $\tau_{c L}$ on low-skill employees in the ESI sectors: to the degree that the low-skill employees are subsidy eligible, the subsidy does not have to be clawed back from ESI employers and those employers are liable for a penalty. ${ }^{52}$ Because the tax rate $\tau_{c L}$ determines coverage decisions and the allocation of labor, window-dressing affects our predictions for these behaviors. Second, we report ESI-participating employees as the number of employees in the ESI sectors minus the window-dressing rate times the number of low-skill employees in those sectors. A similar approach is followed for calculating NGI-participating employees.

Figure 8 is the same as Figure 2, except that Figure 8 sets the window-dressing rate for low-skill workers at $25 \%$ rather than zero, which means that the full-implementation tax rate on low-skill ESI labor, $\tau_{c L}$, is $28.5 \%$ rather than the $36.8 \%$ shown in Table 2 . The equilibrium sector profiles for employment, skill-intensity, and sector prices are broadly similar in the two figures. As a result, our estimates of the ACA's impacts on real wages and productivity do not depend much on the assumed window-dressing rate (see also Table 7). Both window-dressing rates predict a fifteen million increase in participation in private health insurance as a consequence of the ACA.

Although window dressing does not matter much for most of the economic outcomes listed in Table 7, it matters for employers' coverage decisions because low- and high-skill employees no longer have to take the same coverage. Figure 8 shows that $25 \%$ window dressing implies that a few sectors ( 0.59 to 0.62$)$ actually offer ESI under the ACA when they would not offer it absent the ACA, although the ACA's impact on nationwide ESI participation is still negative because of the low-skill employees of ESI employers who end up on the exchanges.

Figure 9 illustrates how window dressing can either reduce or increase ESI participation (compared to an ACA without window dressing), depending on the value of the subsidy implementation rate. An ACA with window dressing reduces ESI participation even when all sectors with ESI retain it because a fraction of the low-skill employees in those sectors can get

\footnotetext{
${ }^{52}$ The effect of window-dressing on $\tau_{c L}$ can be in either direction, depending on the implementation rates for subsidies and penalties.
} 
subsidized coverage on the exchanges instead. However, window dressing helps high-skill employees keep their ESI despite the demand for NGI from their low-skill coworkers. As a result, when the implementation subsidy rate is close to one, an ACA with window dressing does somewhat less to reduce ESI participation than an ACA without it: Figure 9's red line is above its blue one.

Overall, window dressing reduces the range of predicted exchange plan participation and ESI participation impacts. With window dressing, the ACA reduces ESI participation between 3 and 32 million. 
Table 1. Components of Compensation and Employer Costs

Low-skill employees

Empirical Measure

Employer cost $=$ value marginal product of labor

-emolover nenaltv and emplover navroll taxes

$=$ employee compensation (including fringes)

-foregone HU subsidv

$=$ employee comp. net of sector-specific health terms -personal taxes and forgone household subsidies

$=$ reward to work

\begin{tabular}{|c|c|c|c|}
\hline \multicolumn{4}{|c|}{ Model notation by sector } \\
\hline $\begin{array}{r}\underline{\mathrm{ESI}} \\
(1+\tau+c L) w\end{array}$ & $(1+\tau-n \underline{\text { NGI }}$ & $\frac{\text { Uninsured }}{(1+\tau-u L) w}$ & $\frac{\text { Notes }}{\text { varies by sector }}$ \\
\hline$\left(1+\tau \_c L-0.0765\right) w$ & $w$ & $\left(1+\tau \_u L-\tau \_n L\right) w$ & varies by sector \\
\hline$w$ & $w$ & $w$ & $\begin{array}{c}\text { employees are } \\
\text { indifferent }\end{array}$ \\
\hline$\left.s_{-} L\right) w$ & $\left(1-s_{-} L\right) w$ & $\left(1-s_{-} L\right) w$ & between sectors \\
\hline
\end{tabular}

$\underline{\text { Notes }}$

(1) ESI = Employer-sponsored health insurance, $\mathrm{NGI}=$ Non-group health insurance

(2) underscore indicates subscript

(3) 0.0765 is the employer payroll tax rate

(4) $\left(\tau \_c L-0.0765\right) w$ is the value of the exchange subsidy net of the value of the ESI tax exclusion

(5) $(\tau+n L-0.0765) w$ is the employer penalty

(6) $\left(\tau \_u L-0.0765\right) w$ is the value of the exchange subsidy plus the employer penalty 
Table 2. Employer Tax Rate Calibration

Tax amounts expressed as an equivalent salary increment, in 2014 dollars. Assumes full implementation.

\begin{tabular}{cccc}
$\begin{array}{c}\text { without ACA } \\
\text { high skill }\end{array}$ & $\underline{\text { low skill }}$ & $\underline{\text { high skill }}$ & low skill \\
\multicolumn{4}{c}{ Tax Amounts, excluding payroll tax } \\
$-2,554$ & $-2,421$ & $-1,562$ & 7,363 \\
0 & 0 & 2,694 & 2,295 \\
0 & 0 & 6,027 & 13,192
\end{tabular}

Employer type

Tax Rates, including payroll tax

ESI: $\tau_{c K} \& \tau_{c L}$

$\begin{array}{llll}4.6 \% & 0.2 \% & 5.8 \% & 36.8 \%\end{array}$

NGI: $\tau_{n K} \& \tau_{n L}$

$7.7 \% \quad 7.7 \%$

$11.2 \% \quad 15.6 \%$

uninsured: $\tau_{u K} \& \tau_{u L}$

$7.7 \% \quad 7.7 \%$

$15.8 \% \quad 65.9 \%$

$\underline{\text { Sectoral trades }}$

Labor market terms of skill trade distortions

uninsured vs ESI: $q_{u c}$ 1.04

1.11

NGI vs ESI: $q_{n c}$

1.04

0.80

uninsured vs NGI: $q_{\text {un }}$

1.00

1.38

Notes: Tax rates are employer rates: tax amounts are excluded from the base.

See Table 3 for components of the tax amounts 
Table 3. Components of Sector-specific Employer Taxes and Subsidies

Assumes full implementation.

Non-ACA Provisions

Value of excluding health premiums from personal taxes

\section{ACA Provisions}

Employer shared responsibility payment

Full time, full year amount

Adjustment for propensity to work part time ${ }^{\mathrm{a}}$

Avg. salary equivalent (assuming 39\% business tax rate)

Majormedical reinsurance assessment

Exchange subsidy clawback ${ }^{\mathrm{b}}$

Full year amount after personal taxes ${ }^{\mathrm{a}}$

Salary equivalent $\mathrm{a}^{\mathrm{a}}$ (assuming $25 \%$ personal tax rate)

Individual mandate penalty (salary equivalent) ${ }^{\mathrm{c}}$

TOTAL $^{\mathrm{a}}=$ sum of applicable annual salary equivalent amounts

TOTAL $^{\mathrm{a}}$ adjusted for average weeks worked per year
Applicable sector?

\begin{tabular}{|c|c|c|c|}
\hline \multirow{2}{*}{$\frac{\text { Annual Amount }}{-2,660}$} & \multirow{2}{*}{$\frac{\text { ESI }}{\text { yes }}$} & \multicolumn{2}{|c|}{ NGI uninsured } \\
\hline & & $\overline{\text { no }}$ & $\overline{\text { no }}$ \\
\hline \multirow[t]{2}{*}{$\underline{\text { Annual Amount }}$} & \multirow{2}{*}{$\frac{\text { ESI }}{\text { no }}$} & \multicolumn{2}{|c|}{ NGI uninsured } \\
\hline & & yes & yes \\
\hline 2,000 & & & \\
\hline 1,656 & & & \\
\hline 2,522 & & & \\
\hline 126 & yes & no & no \\
\hline & yes & no & yes \\
\hline 7,968 & & & \\
\hline 10,624 & & & \\
\hline 1,348 & no & no & yes \\
\hline its & 8,090 & 2,522 & 14,494 \\
\hline & 7,363 & 2,295 & 13,192 \\
\hline
\end{tabular}

Notes: ${ }^{\text {a }}$ The amount shown in the table is for low-skill. We use an alternate amount for high-skill workers.

${ }^{b}$ For use in a model in which all employees receive an exchange subsidy by default.

${ }^{\mathrm{c}}$ Scaled down by an estimated $20 \%$ of uninsured low-skill workers who are illegal immigrants. 
Table 4. Industries and States With Low and High Fractions of Workers under 300\% Poverty March 2012 CPS

Top 5 Low-Skill Intensive Industries

Services to buildings and dwellings

Restaurants and other food services

Landscaping services

Employment services

Crop production

\section{Low-skill share}

0.72

0.71

0.65

0.63

0.63
Share of workers

with ESI in own name

0.18

0.24

0.22

0.29

0.20

Bottom 5 Low-Skill Intensive Industries

Securities, commodities, funds, \& other financial

0.10

0.71

Architectural, engineering

0.12

0.69

National security and international affairs

0.13

0.78

Computer systems design

0.14

0.73

Electric power generation and distribution

0.15

0.89

Top 5 Low-Skill Intensive States

Idaho

0.46

0.52

Arkansas

0.45

0.56

South Carolina

0.45

0.57

Utah

0.45

0.54

New Mexico

0.45

0.46

Bottom 5 Low-Skill Intensive States

New Hampshire

0.23

0.58

District of Columbia

0.25

0.65

Connecticut

0.25

0.60

Massachusetts

0.25

0.59

Maryland

0.25

Notes: Low-skill is defined to be living in a family under $300 \%$ of the Federal Poverty Line. Industries are limited to those 54 employing at least $0.5 \%$ of non-elderly heads and spouses. 


\section{Table 5. Industries and States with Workers at Risk of Losing ESI}

March 2012 CPS, limited to industries employing at least $0.5 \%$ of non-elderly heads and spouses

Share of

Top 5 industries by share of full-time employees at risk of losing $\mathrm{F}$

Department stores and discount stores

$\underline{\text { workers at risk }}$

Traveler accommodation

0.51

Grocery stores

0.50

Nursing care facilities

0.47

Clothing stores

0.47

0.38

Top 5 states

Mississippi

0.23

Nevada

0.23

Arkansas

0.21

South Carolina

0.18

Tennessee

0.18

Bottom 5 states

District of Columbia

0.04

Connecticut

0.05

Alaska

0.05

Massachusetts

0.06

New Hampshire

0.06

Note: "at risk" means (i) having ESI in own name and (ii) industry and state estimated to be low-skill intensive enough that the average employee's subsidy from the exchanges exceeds ESI's implicit 


\section{Table 6. Model Parameters}

Baseline Factor Allocation

low-skill employees with ESI

20.1

total low-skill employees

high-skill employees with ESI

33.9

59.8 March 2012 CPS

total high-skill employees

67.5

ESI participants per covered worker

2.0 ratio of total ESI plan participants

(CBO) to ESI employees

Substitution Parameters

ESI offer elasticity with respect to the price of ESI $\quad 0.333$

elasticity of factor substitution in production $\quad 1.5$

elasticity of sectoral substitution in utility

wage elasticity of labor supply

1.0 also Leontief preferences

0.5 also inelastic labor supply

Other Technology Parameters

baseline marginal revenue product of low-skill labor 32,381

baseline marginal revenue product of high-skill labor 82,813

ESI post-tax expenditures per $\$$ of covered earnings $\quad 0.09$

Productivity parameters $A$ and $z$

factor intensity parameter $\alpha$ for:

the most skill-intenstive sector

0.09 fits baseline factor allocation and

the least skill-intenstive sector

0.44

productivity

Other Taste Parameters

sectoral gradient of consumer preferences

-2.8 fits baseline factor allocation and

slope of sectoral gradient of consumer preferences

4.2 skill-specific productivity

Employer Tax Rates

See Table 2 for full-implementation tax rates by sector and skill level

Additional Employee Tax Rates (uniform by sector, and unaffected by the ACA)

low-skill

$50 \%$ Mulligan (2013)

high-skill

44\% Mulligan (2013) 
Table 7. ACA Impacts with and without Window Dressing

Percentage of low-skill employees at ESI employers who receive subsidies

Penalties Implemented 50\%

ESI participation

$25 \%$

NGI participation

$-12.8$

$-25.4$

28.1

participation in private insurance

40.5

$\log$ productivity (fixed labor supply)

$15.0 \quad 15.2$

Penalties Implemented 100\%

log real low-skill wage (fixed labor supply)

$-0.005$

$-0.005$

log reward to low-skill work (fixed labor supply)

$-0.01$

0.01

log productivity (fixed labor supply)

$-0.25$

$-0.23$

full-implementation tax rate on low-skill ESI labor, $\tau_{c L}$

$-0.008$

$-0.008$

$36.8 \% \quad 28.5 \%$

Note: Subsidies are assumed to be $80 \%$ implemented. Participation is measured in millions. 


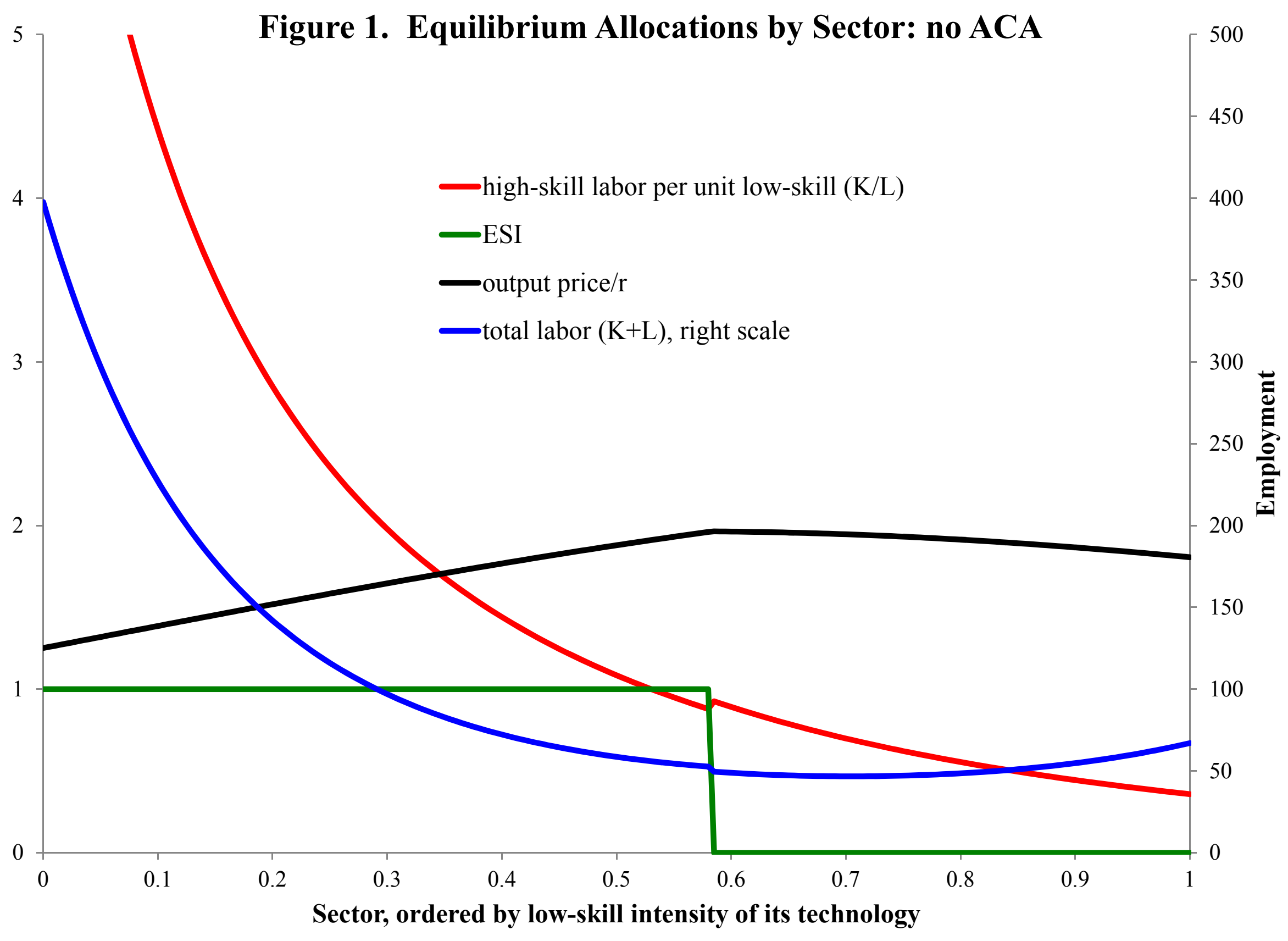




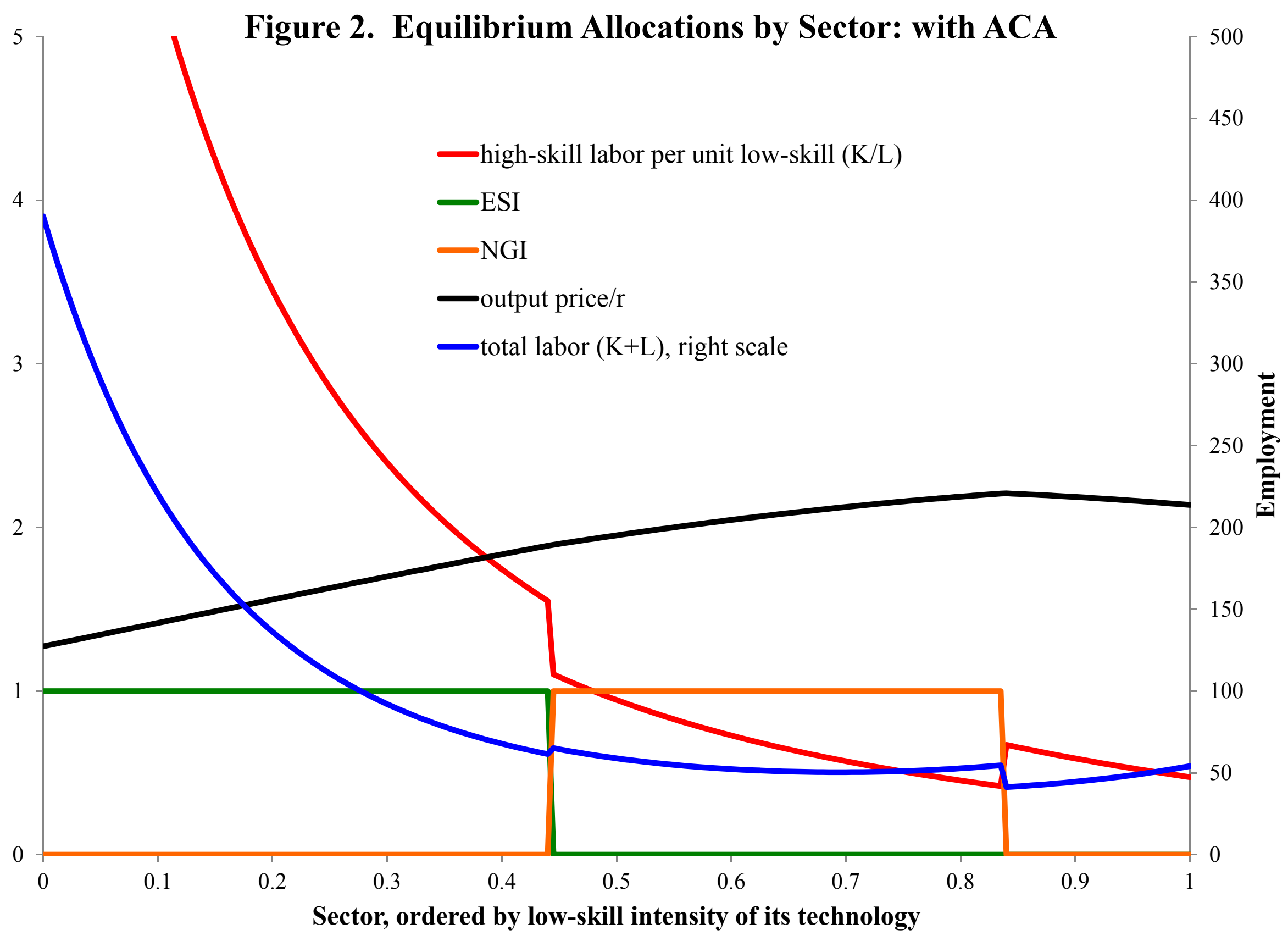




\section{Figure 3. Compensation Ratios and the Surplus from ESI}

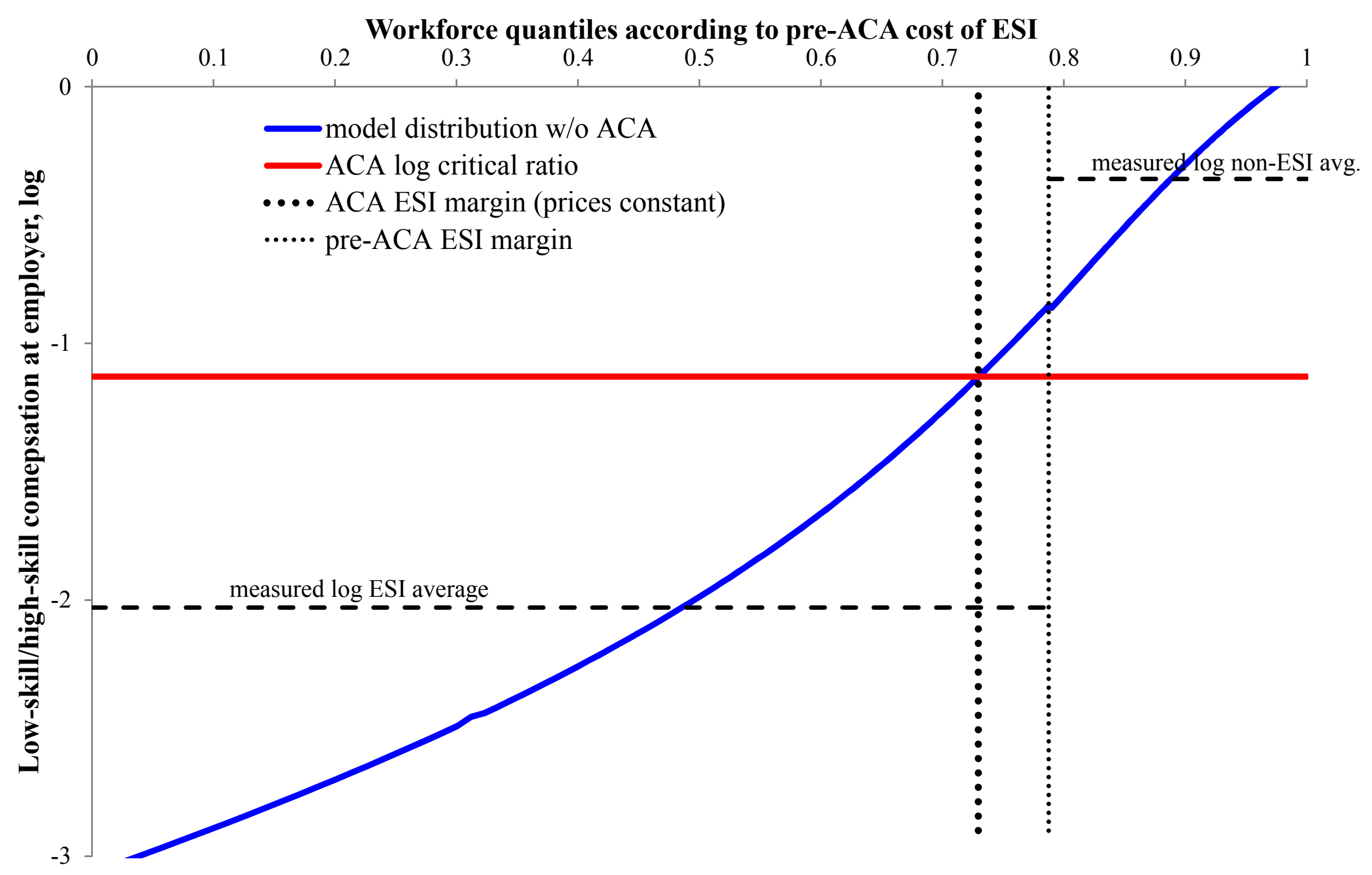




\section{Figure 4. The ACA's ESI Impact}

As a function of subsidy and penalty implementation

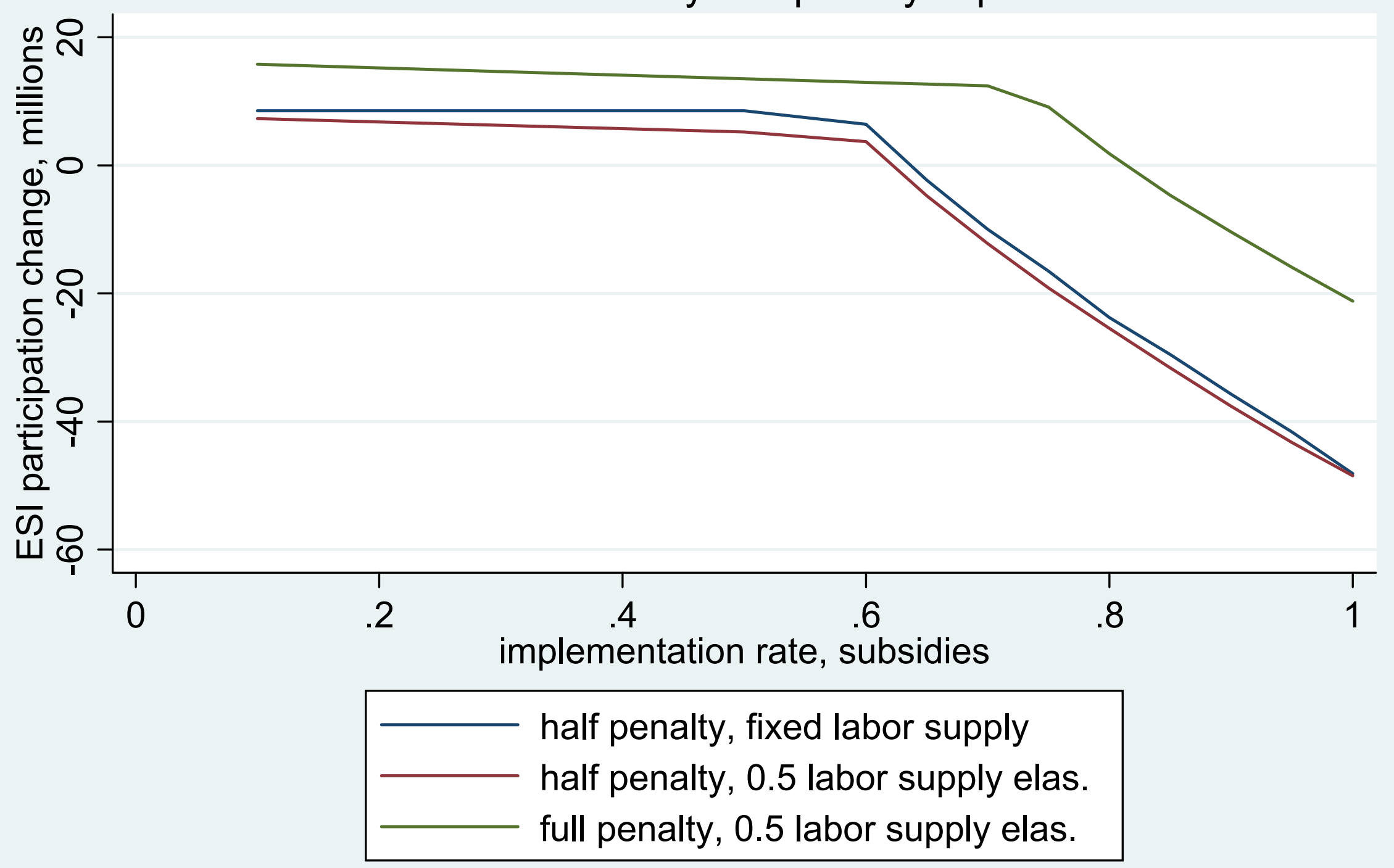


Figure 5. The ACA Affects Coverage through Labor Market Behavior

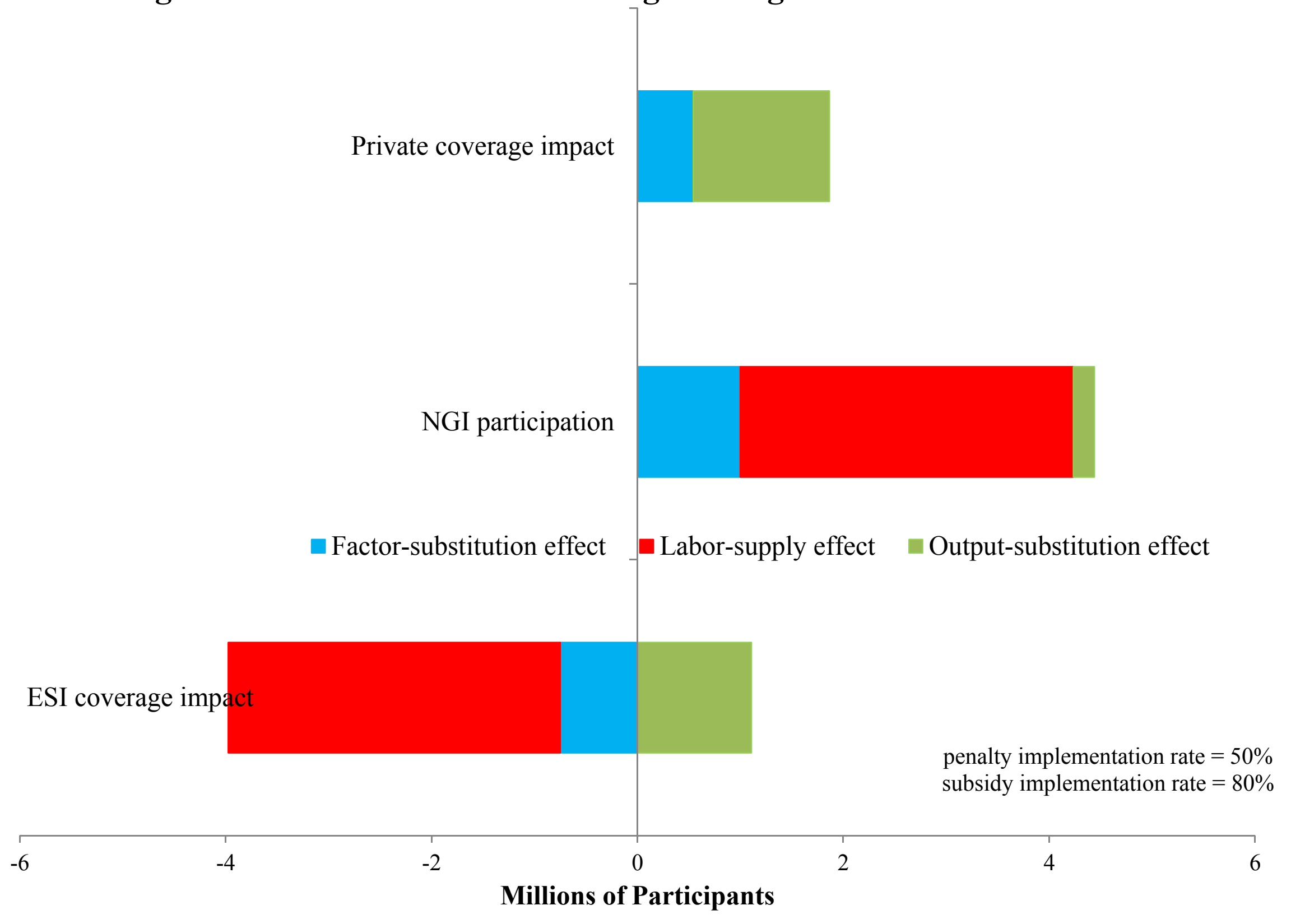




\section{Figure 6. Insuring the Uninsured}

As a function of subsidy and penalty implementation

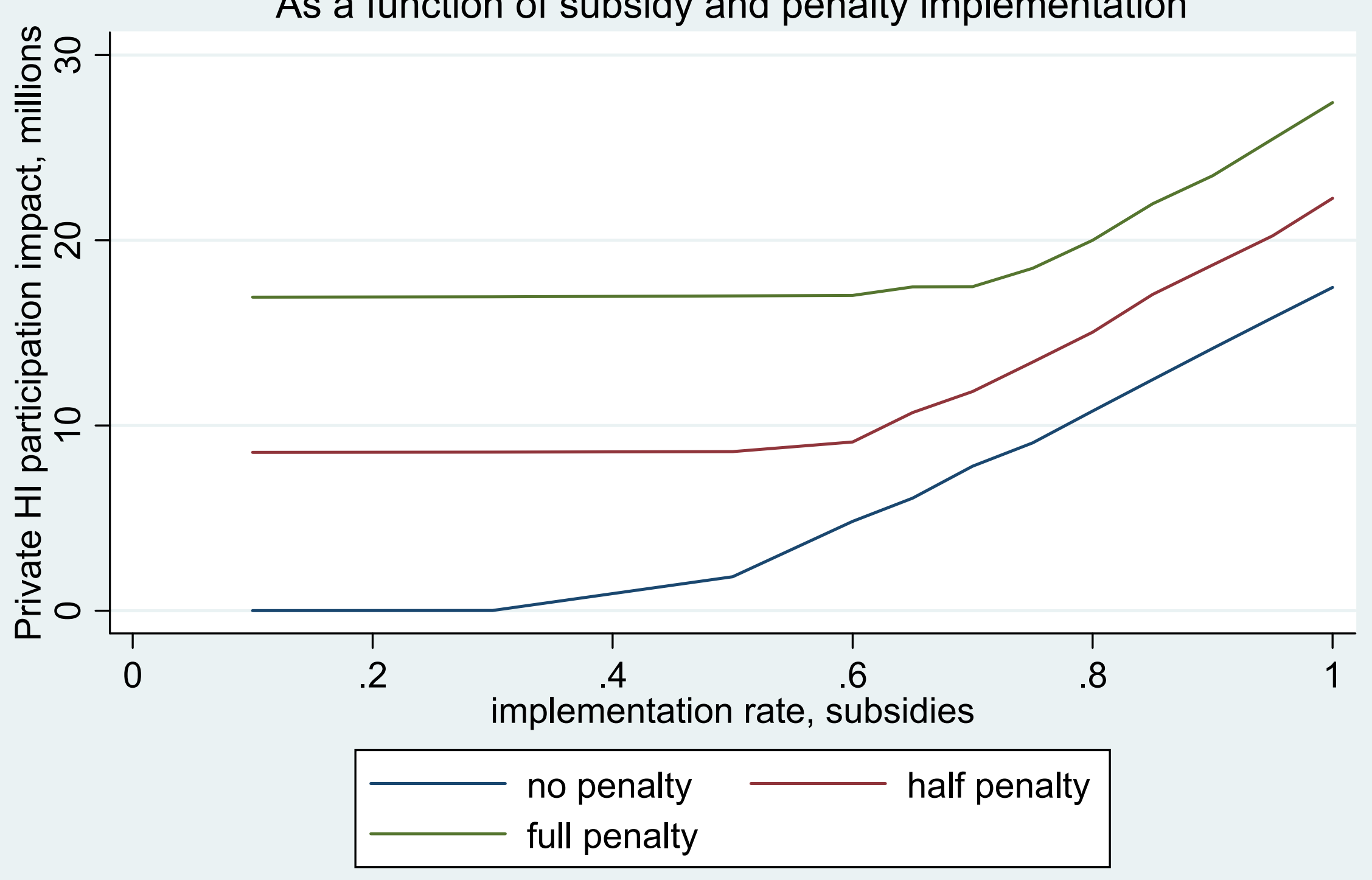




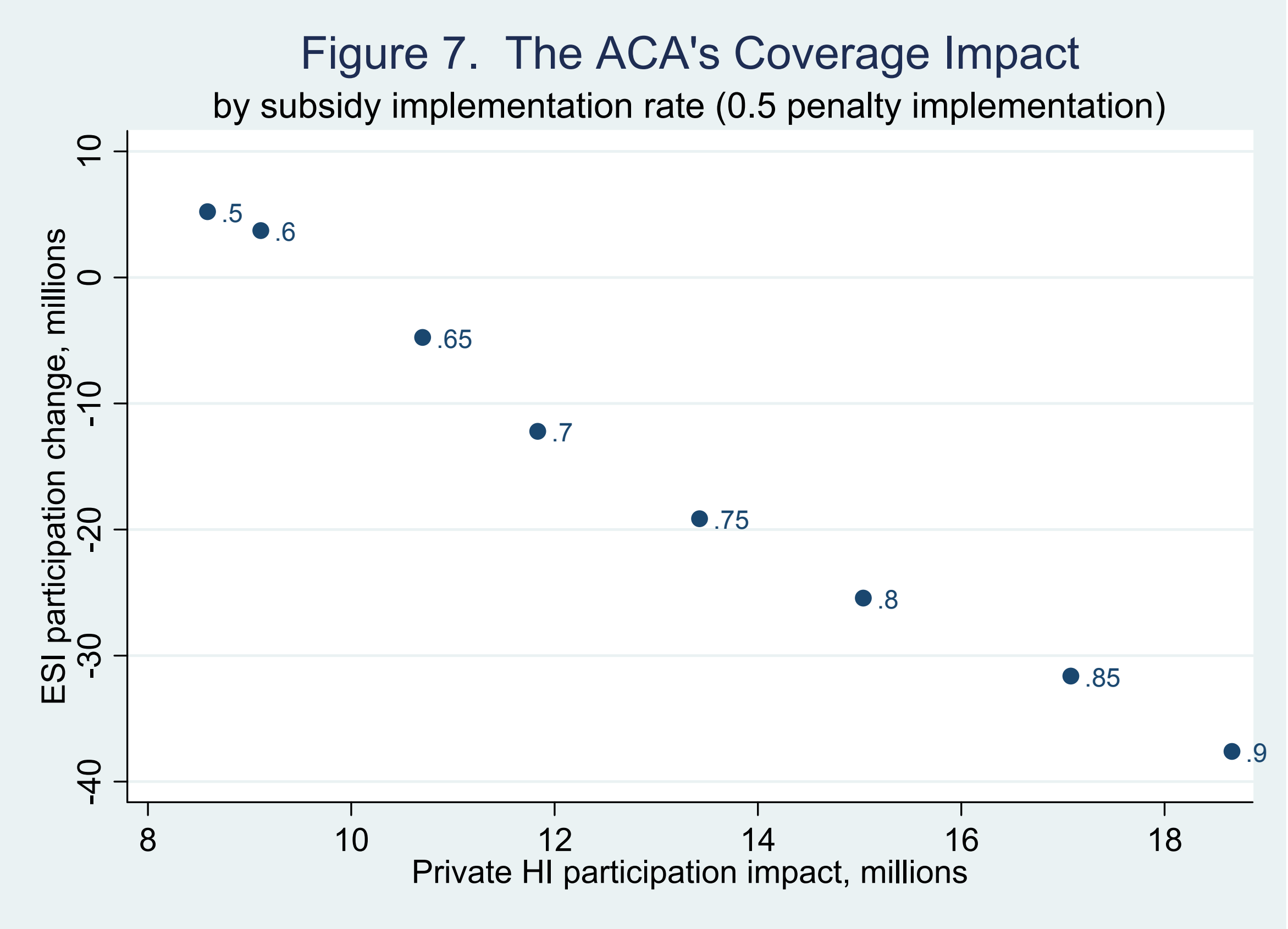




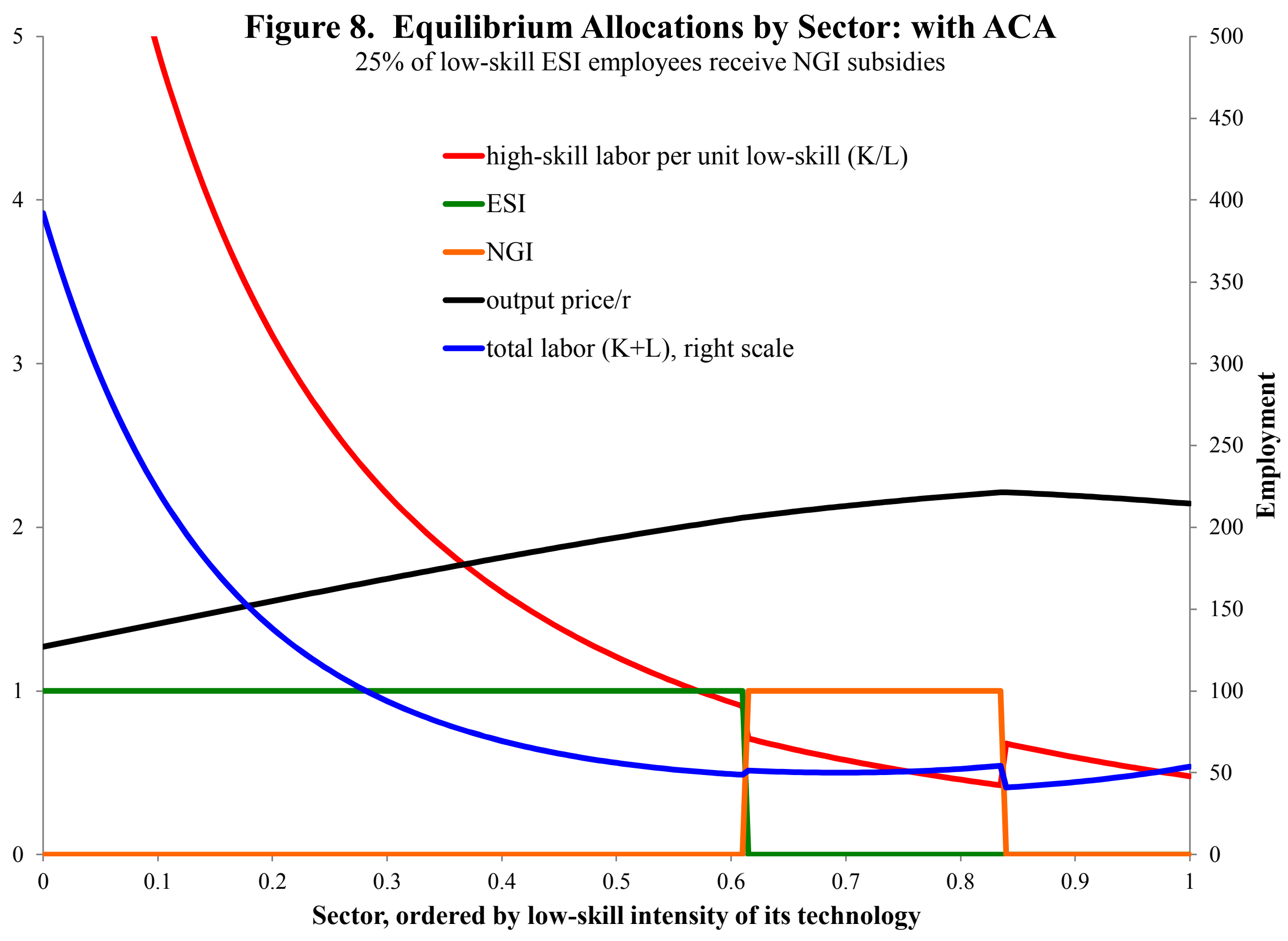


Figure 9. The Window-dressing Margin and ESI Participation

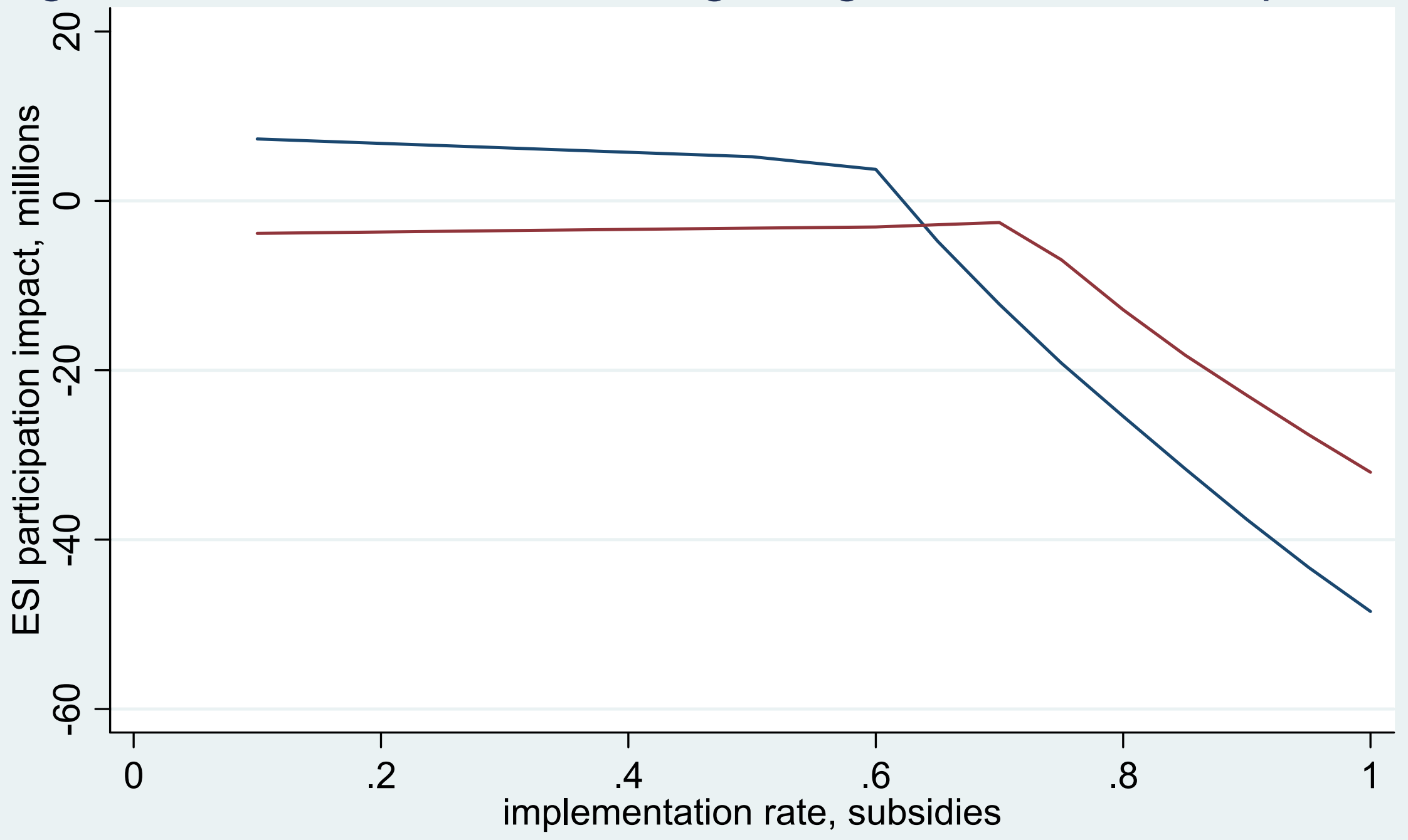




\section{Bibliography}

Acemoglu, Daron. "Technical Change, Inequality, and the Labor Market." Journal of Economic Literature 40 (March 2002): 7-72.

Buchmueller, Thomas, Colleen Carey, and Helen G. Levy. "Will Employers Drop Health Insurance Coverage Because Of The Affordable Care Act?" Health Affairs 32, no. 9 (September 2013): 1522-30.

Burkhauser, Richard V., Sean Lyons, and Kosali I. Simon. "The Importance of the Meaning and Measurement of "Affordable" in the Affordable Care Act." NBER working paper, no. 17279 (September 2011).

Carter, Susan B., Scott Sigmund Gartner, Michael R. Haines, Alan L. Olmstead, Richard Sutch, and Gavin Wright. Historical Statistics of the United States: Millenial Edition Online. 2013.

Congressional Budget Office. "CBO's Health Insurance Simulation Model: A Technical Description." CBO Background Paper, October 2007.

-. "Estimate of the Effects of the Affordable Care Act on Health Insurance Coverage." Congressional Budget Office. February 2013. http://www.cbo.gov/sites/default/files/cbofiles/attachments/43900_ACAInsuranceCovera geEffects.pdf (accessed July 24, 2013).

Dubay, Lisa, Sharon K. Long, and Emily Lawton. Will Health Reform Lead to Job Loss? Evidence from Massachusetts Says No. Urban Institute, 2012.

Eibner, Christine, and Carter C. Price. "The Effect of the Affordable Care Act on Enrollment and Premiums, with and without the Individual Mandate." RAND Corporation Technical Report, 2012.

Gabel, Jon R., et al. "More Than Half Of Individual Health Plans Offer Coverage That Falls Short Of What Can Be Sold Through Exchanges As Of 2014." Health Affairs 31, no. 6 (June 2012): 1-12.

Gallen, Trevor. "Size Provisions in the Affordable Care Act." manuscript, University of Chicago, 2013.

Gruber, Jonathan. "2011 Hewitt Health Care Lecture: The Budgetary Impact of Federal Health Care Reform." vimeo.com. March 2011. http://vimeo.com/21114715\#t=27m2s (accessed August 8, 2013).

Hancock, Jay. "FAQ: How Employer-Sponsored Health Insurance is Changing." kaiserhealthnews.org. September 17, 2013. 
http://www.kaiserhealthnews.org/Stories/2013/September/17/employer-sponsored-healthinsurance-trends.aspx (accessed September 20, 2013).

Harberger, Arnold C. "The Incidence of the Corporation Income Tax." Journal of Political Economy 70, no. 3 (June 1962): 216-40.

Mathews, Anna Wilde. "Price, Price, Price: Health-Insurance Shoppers Have Priorities." Wall Street Journal, July 14, 2013.

Mulligan, Casey B. "Average Marginal Tax Rates under the Affordable Care Act." NBER working paper, August 2013.

Mulligan, Casey B., and Trevor S. Gallen. "Wedges, Wages, and Productivity under the Affordable Care Act." NBER working paper, December 2013.

Murphy, Tom. "Walgreen moves health coverage to private exchange." U.S. News and World Report, September 18, 2013.

Pear, Robert. "Brawling Over Health Care Moves to Rules on Exchanges." The New York Times, July 7, 2012: A14.

-. "Lower Health Insurance Premiums to Come at Cost of Fewer Choices." The New York Times, September 22, 2013: A1.

PricewaterhouseCoopers. "Health Exchanges: Open for Business." pwchealth.com. September 2013. http://pwchealth.com/cgi-local/hregister.cgi/reg/pwc-provider-health-exchanges09-16-13.pdf (accessed September 23, 2013).

Rennane, Stephanie, and C. Eugene Steuerle. "Health Reform: A Four-Tranche System (Updated and Revised)." www.urban.org. February 22, 2011. http://www.urban.org/publications/901408.html (accessed March 15, 2013).

Terhune, Chad. "Insurers Limit Doctors, Hospitals in State-run Exchange Plans." Los Angeles Times, May 24, 2013.

Unel, Bulent. "Analyzing skilled and unskilled labor efficiencies in the US." Journal of Macroeconomics 32, no. 4 (December 2010): 957-67. 